\title{
ALCOHOL SCREENING
}

AND BRIEF INTERVENTION

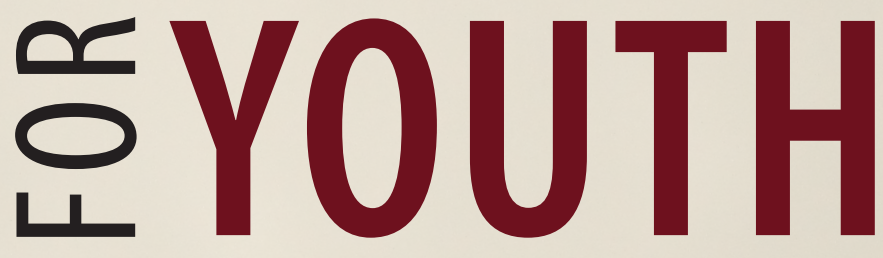

\section{A PRACTITIONER'S GUIDE}

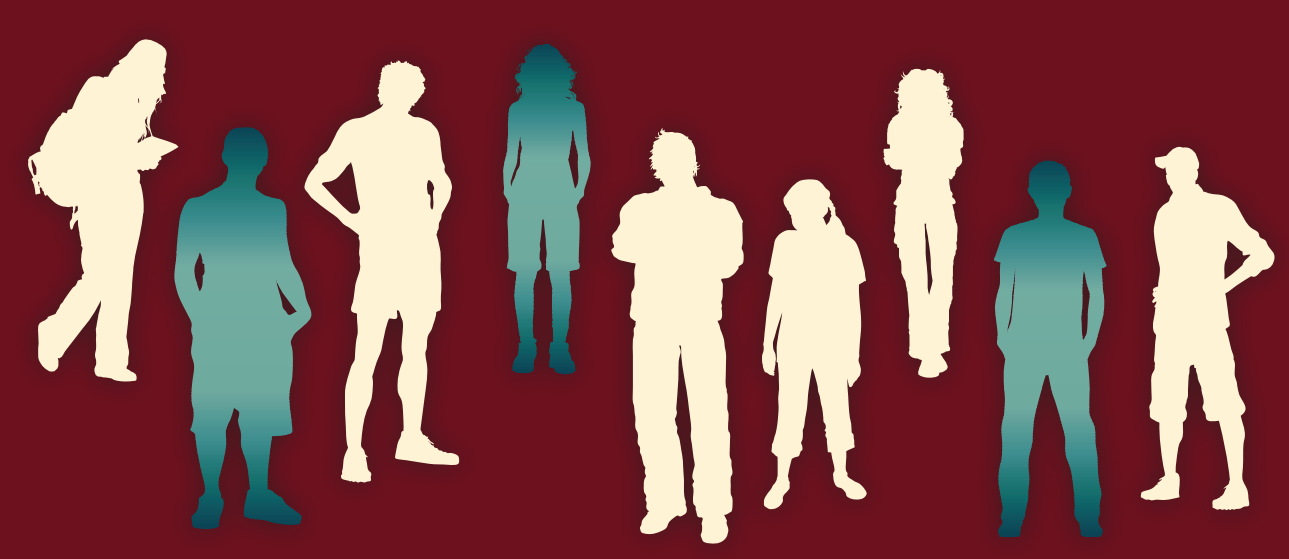

1 in 3 children starts drinking by the end of 8 th grade
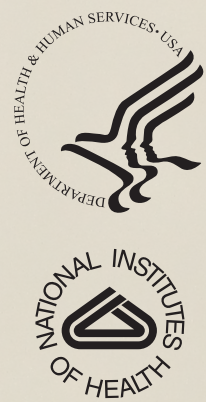


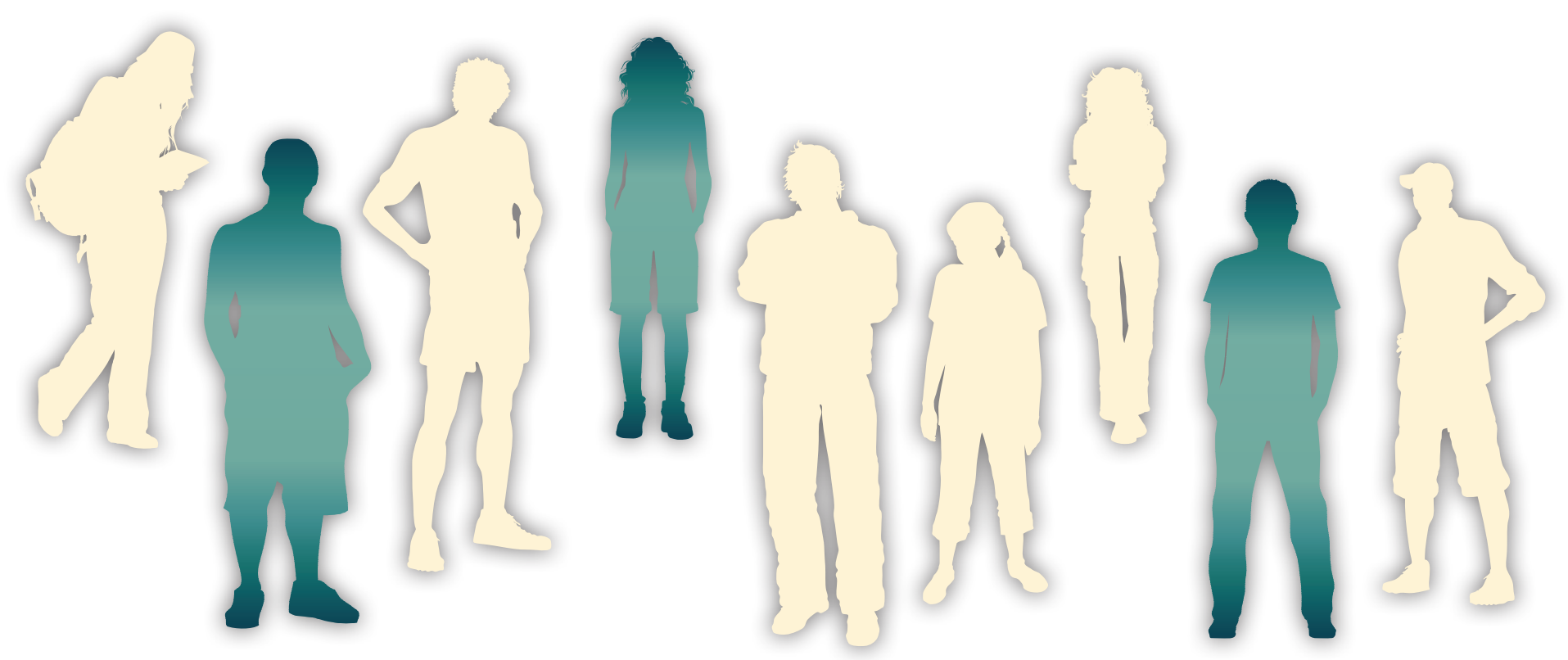

1 in 3 children starts drinking by the end of 8 th grade ... and of them, half report having been drunk. 


\section{CONTENTS}

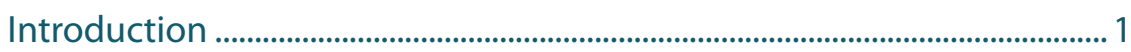

About This Guide ......................................................................................................

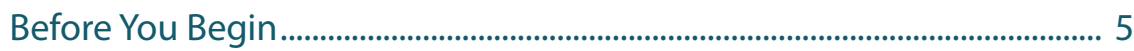

Alcohol Screening and Brief Intervention for Youth Ages 9-18:

Four Steps at a Glance ..............................................................................................

For All Patients:

Step 1: Ask the Two Screening Questions................................................. 8

Step 2: Guide Patients Who Do Not Drink .............................................. 9

or Assess Risk in Patients Who Do Drink ...........................................10

For Patients Who Drink:

Step 3: Advise and Assist............................................................................11

Step 4: At Followup, Continue Support.....................................................12

\section{Appendix}

Frequently Asked Questions ................................................................................14

Clinician Support Materials................................................................................2

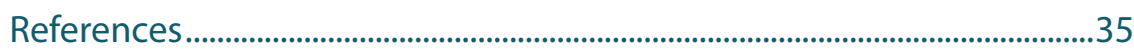

Additional Resources .........................................................................................3 



\section{INTRODUCTION}

With this Guide, the National Institute on Alcohol Abuse and Alcoholism (NIAAA) introduces a simple, quick, empirically derived tool for identifying youth at risk for alcohol-related problems. If you manage the health and well-being of children and adolescents ages 9-18 years, this Guide is for you. It has been produced in collaboration with the American Academy of Pediatrics, clinical researchers, and health practitioners such as yourself.

\section{Why choose this tool?}

It can detect risk early: In contrast to other screens that focus on established alcohol problems, this early detection tool aims to help you prevent alcohol-related problems in your patients before they start or address them at an early stage.

It's empirically based: The screening questions and risk scale, developed through primary survey research, are powerful predictors of current and future negative consequences of alcohol use.

It's fast and versatile: The screen consists of just two questions that you can incorporate easily into patient interviews or pre-visit screening tools across the care spectrum, from annual exams to urgent care.

It's the first tool to include friends' drinking: The "friends" question will help you identify patients at earlier stages of alcohol involvement and target advice to include the important risk factor of friends' drinking.

\section{Why screen for underage drinking?}

It's common: Alcohol is by far the drug of choice among youth. It's often the first one tried, and it's used by the most kids (Johnston et al., 2010). Over the course of adolescence, the proportion of kids who drank in the previous year rises tenfold, from 7 percent of 12-year-olds to nearly 70 percent of 18-year-olds (NIAAA, 2011). Dangerous binge drinking is common and increases with age as well: About 1 in 14 eighth graders, 1 in 6 tenth graders, and 1 in 4 twelfth graders report having five or more drinks in a row in the past 2 weeks (Johnston et al., 2011). Chances are, your practice has its share of youth at risk.

It's risky: In the short term, adolescent drinking too often results in unintentional injuries and death; suicidality; aggression and victimization; infections and pregnancies from unplanned, unprotected sex; and academic and social problems (Brown et al., 2008). In the long term, drinking in adolescence is associated with increased risk for alcohol dependence later in life (Hingson et al., 2006; Grant \& Dawson, 1997). In addition, heavy drinking in adolescence may result in long-lasting functional and structural changes in the brain (Squeglia et al., 2009). 
It's a marker for other unhealthy behaviors: When adolescents screen positive for one risky behavior - whether drinking, smoking tobacco, using illicit drugs, or having unprotected sex-it's generally a good marker for the others (Biglan et al., 2004). For many kids, drinking alcohol is the first risky behavior tried. So the quick alcohol screen in this Guide can alert you to patients who may need attention for other risky behaviors as well.

It often goes undetected: Most adolescents visit a primary care practitioner every year or two (O'Connor et al., 1999), and many are willing to discuss alcohol use when they are assured of confidentiality (Ford et al., 1997). However, the majority of clinicians do not follow professional guidelines to screen all of their adolescent patients for alcohol use, often citing a lack of confidence in their alcohol management skills as a barrier (Millstein \& Marcell, 2003). To offer support in this area, this Guide includes an overview of a promising, teen-friendly approach to promoting positive change in young drinkers (see page 29).

As a trusted health care provider, you are in a prime position to identify drinking-related risks and problems in your patients and to intervene. Our hope is that the brevity, ease of use, and predictive strength of this new tool will enable you to detect alcohol risks and prevent harm at the earliest possible stage. With this Guide, you have what you need to begin. 


\section{ABOUT THIS GUIDE}

NIAAA created this Guide to help you conduct fast, effective alcohol screens and interventions with your patients, even during brief, acute care visits. The tools, tips, and resources are designed to help you surmount common obstacles to youth alcohol screening in primary care. Typical barriers include insufficient time, unfamiliarity with screening tools, the need to triage competing problems, and uncertainty about how to manage a positive screen (Van Hook et al., 2007).

\section{It's about time-yours and your patients'}

In primary care, your time is at a premium. Time is also of the essence for your patients who may be considering, experimenting with, using, abusing, or even becoming dependent on alcohol. With this in mind, we wanted you to have the shortest possible alcohol screening tool with the strongest evidence for predicting current or downstream problems in youth. To reach this goal, NIAAA convened a working group of researchers who conducted primary analyses of multiple databases across multiple years. Their extensive analyses boiled down to two questions per patient, varying slightly by age group.

\section{Two powerful questions open the door}

One question is about friends' drinking, and the other is about personal drinking frequency (see page 8). The friends' drinking question is an early warning signal that strongly predicts the patient's future drinking levels (Brown et al., 2010). It also allows you a nonthreatening "sidedoor" entrance to begin talking about alcohol with younger patients in particular. The personal drinking question zeroes in on frequency, the best predictor of current risk for alcohol-related harm in adolescents who are already drinking (Smith et al., 2010). The researchers examined many other questions, but these two by far had the greatest practicality and predictive strength. If you're going to ask about alcohol, these are the questions to ask. (For details about the development of the questions, see page 16 and visit www.niaaa.nih.gov/YouthGuide.)

\section{The risk estimator can help you triage}

Acute care visits generally don't allow time for anticipatory guidance. Even during well-care visits, you'll need to choose the guidance to offer. The risk estimator (see page 10 and the Pocket Guide) broadly indicates your patient's chances for having alcohol-related problems, based on his or her age and drinking frequency. Coupled with what you already know about your patient, it will help you determine the depth and content of your response. 


\section{Positive screens become manageable}

This Guide's tools will take much of the mystery out of intervening with your patients who are drinking, allowing you to proceed within a clinical framework of lower, moderate, or highest risk (see page 11). Once you determine that a patient is at lower risk, for example, you'll be able to provide brief advice, quickly and with confidence, and move on. For patients at moderate or highest risk for alcohol-related harm, you will have uncovered perhaps the greatest current threat to their health - and still, you can manage it efficiently. The Guide outlines different levels of intervention with tips for topics to cover. It also presents an overview of brief motivational interviewing, an interactive, youth-friendly intervention considered to have the best potential effectiveness for the adolescent population (see page 29).

In addition, the Guide aims to help clinicians overcome other common barriers to screening: concerns about confidentiality (see page 25), a lack of information about coding for counseling about alcohol use (see page 24), and the challenge of finding adolescent treatment resources for referrals (see page 34).

In short, our goal is to support your efforts to protect your patients from alcohol-related harm. And we want to hear from you. Please send us your comments about this Guide - and suggestions for ways to improve our support for you—by email to NIAAAYouthGuide@mail.nih.gov. 


\section{BEFORE YOU BEGIN}

\section{Decide on a screening method}

The screening questions can be used at any time, alone or along with other tools, as part of a clinical interview. Some practices may prefer to incorporate the questions into written self-report questionnaires or computer screening that patients complete before seeing the clinician. You will need to protect patient privacy, of course, whether you ask the questions in person or by other means.

\section{Think about opportunities and clinical indications for screening}

- As part of an annual examination

- As part of an acute care visit

- In the emergency department or urgent care center

- When seeing patients who:

- you have not seen in a while

- are likely to drink, such as youth who smoke cigarettes

- have conditions associated with increased risk for substance abuse, such as:

$$
\begin{array}{ll}
\text { - depression } & \text { - ADD/ADHD } \\
\text { - anxiety } & \text { - conduct problems }
\end{array}
$$

- have health problems that might be alcohol related, such as:

- accidents or injury

- sexually transmitted infections or unintended pregnancy
- changes in eating or sleeping patterns

- gastrointestinal disturbances

- chronic pain

- show substantial behavioral changes, such as:

- increased oppositional behavior

- significant mood changes

- loss of interest in activities
- change of friends

- a drop in grade point average

- large number of unexcused school absences 


\section{Set up your practice to simplify the process}

- Educate office staff: Ensure that staff members understand the importance of universal alcohol screening for youth. Identify a lead "champion" to establish, monitor, and evaluate office screening procedures.

- Decide how screening will be conducted: If a clinical assistant will screen instead of the physician, or if a print or computerized tool is used, work out record-keeping to facilitate followup in the exam room. Commit to screening at every possible visit.

- Set reminders: If available, use electronic medical records to cue for screening and followup.

- Prepare for confidential care: Establish procedures for providing confidential care. Become familiar with your State laws on a minor's ability to consent to substance use treatment (see page 25).

- Prepare for referrals: Generate a list of, and build a rapport with, local adolescent alcohol treatment resources (see page 34); keep copies of the list in exam rooms.

- Stock materials: Keep copies of the Pocket Guide (provided) in exam rooms. Provide educational materials for parents (see page 38). 


\section{FOUR STEPS AT A GLANCE}

Refer to the following pages for detailed steps.

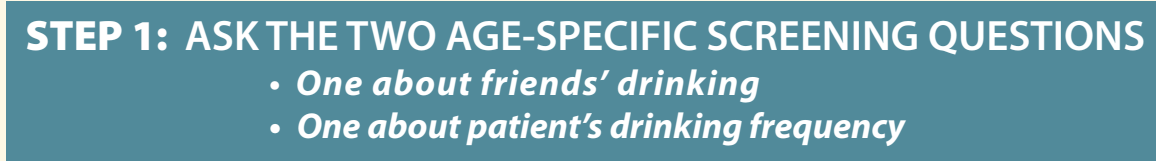

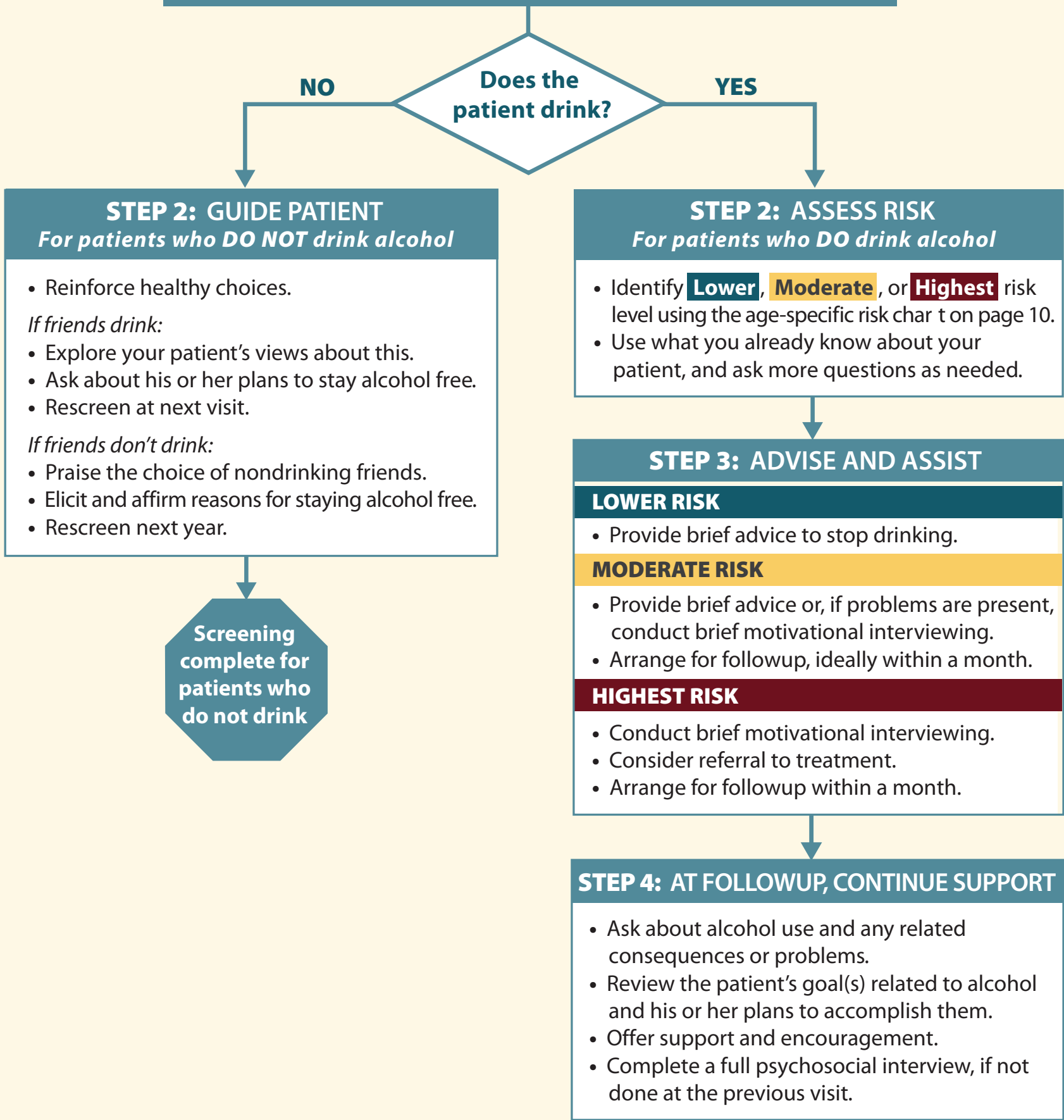




\section{STEP 1: ASK THE TWO SCREENING QUESTIONS}

Research indicates that the two age-specific screening questions (about friends' and patient's drinking) are powerful predictors of current and future alcohol problems in youth. Fit them into your office practice in whatever way works best for you, whether by adding them to a pre-visit screening tool or weaving them into your clinical interview. In either case, take steps to protect patient privacy and, if at all possible, conduct an in-person alcohol screen when you are alone with your patient. See page 25 for more information about confidentiality.

Guidelines for asking the screening questions: (1) For elementary and middle school patients, start with the friends question, a less threatening, side-door opener to the topic of drinking.

(2) Because transitions to middle or high school increase risk, choose the question set that aligns with a patient's school level, as opposed to age, for patients aged 11 or 14. (3) Exclude alcohol use for religious purposes.

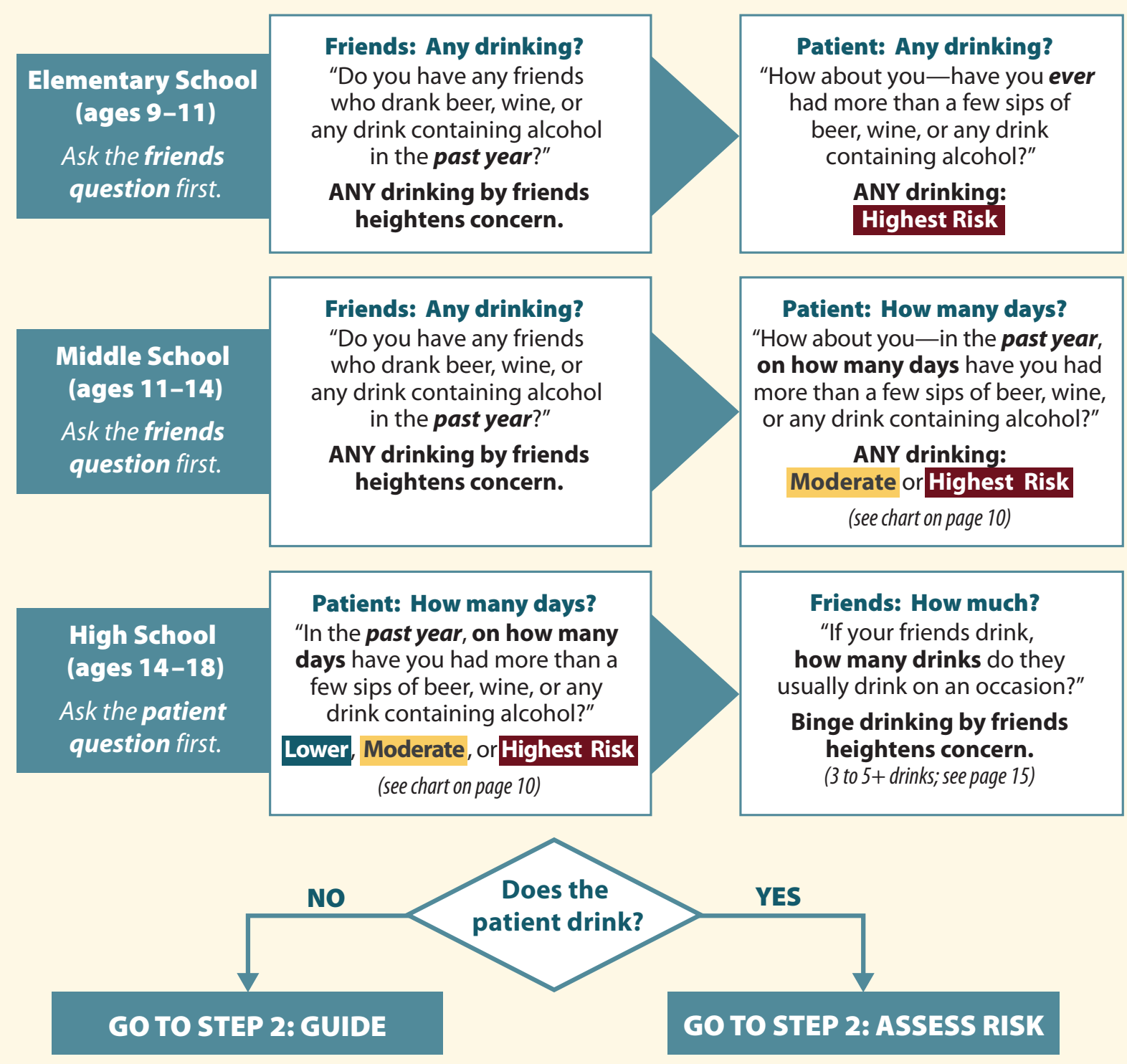

8 Alcohol Screening and Brief Intervention for Youth | A Practitioner's Guide 


\section{STEP 2: GUIDE PATIENT}

For patients who DO NOT drink ...

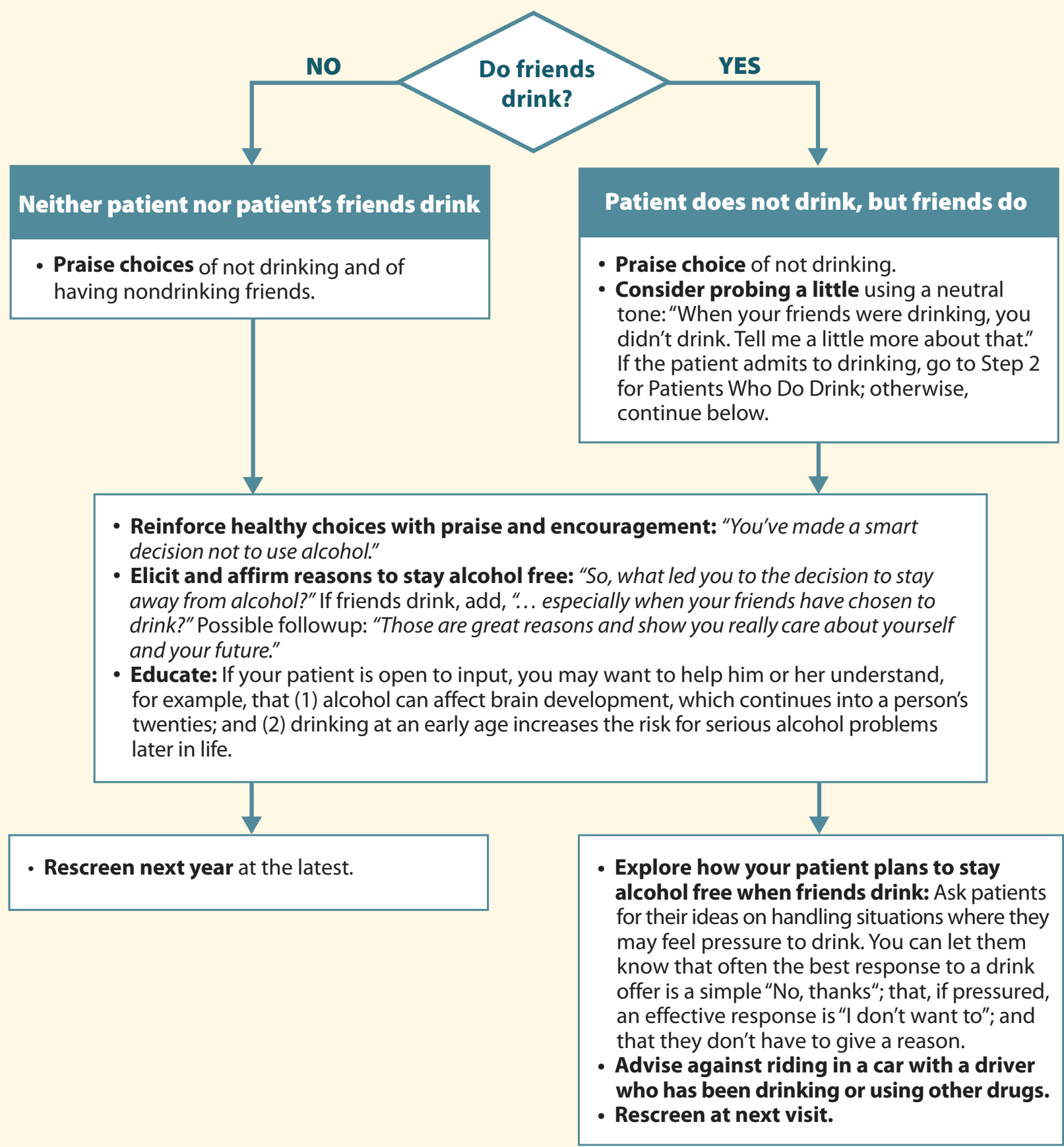




\section{STEP 2: ASSESS RISK \\ For patients who DO drink...}

For a broad indicator of your patient's level of risk, start with the chart below, which provides empirically derived population-based estimates. Then factor in what you know about friends' drinking and other risk factors, ask more questions as needed, and apply your clinical judgment to gauge the level of risk.

\section{On how many DAYS in the past year did your patient drink?}

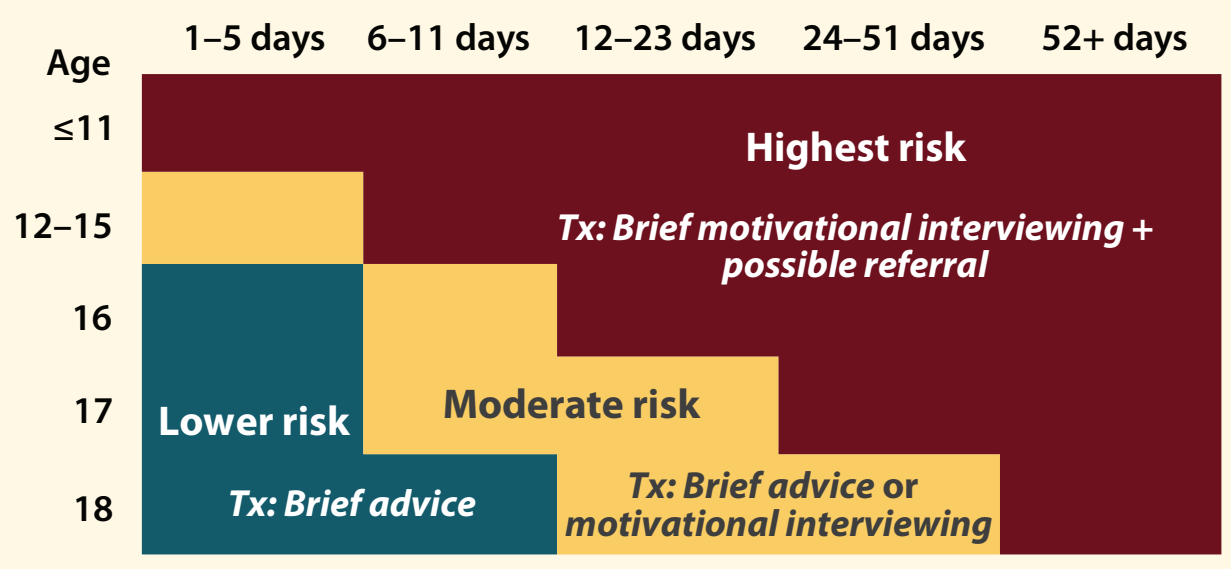

Estimated risk levels by age and frequency in the past year

In the chart, see where your patient's age and drinking frequency intersect: If your patient responds to the screening question with a per-month or per-week frequency, convert the answer to days per year to see where the drinking falls on the risk chart. As an example, a 15-year-old who reports drinking about twice a month, or 24 days in the past year, is at "highest risk" for adverse consequences. (This chart is also in the Pocket Guide; see page 19 for tips on remembering the risk level cut points.)

Factor in friends:

- For elementary and middle school students: Having friends who drink heightens concern. Because having more drinking friends means more risk, ask how many friends drink, if your patient didn't offer this detail when answering the screening question.

- For high school students: Having friends who binge drink heightens concern. Recent research estimates that binge drinking levels for youth start at 3 to 5 drinks, depending on age and gender (see page 15).

Include what you already know about the patient's physical and psychosocial development in your risk evaluation, along with other relevant factors such as the level of family support, drinking and smoking habits of parents and siblings, school functioning, or trouble with authority figures.

For moderate and highest risk patients:

- Ask about their drinking pattern: "How much do you usually have? What's the most you've had at any one time? " If the patient reports bingeing (see page 15), ask: "How often do you drink that much?"

- Ask about problems experienced or risks taken: "Some people your age who drink have school problems like lower grades or missed classes. Some do things and feel bad about them later, like damaging or stealing property, getting into fights, getting sexually involved, or driving or riding in a car driven by someone who has been drinking. Others get injured, have memory blackouts, or pass out. What not-so-good things related to drinking, if any, have you experienced?"

- Ask about other substance use ("Have you used anything else to get high in the past year?") and consider using other formal tools to help gauge risk (see page 32). The majority of your lower risk patients will not have used illicit drugs (NIAAA, 2011), but ask them, too, about past-year use, time permitting.

After you assess risk ... GO TO STEP 3 


\title{
STEP 3: ADVISE AND ASSIST
}

\author{
For patients who DO drink ...
}

In this step, conduct a brief intervention for your patients who drink, based on the risk levels identified during Step 2. See the appendix for additional information on confidentiality (page 25) and conducting brief motivational interviewing (page 29).

\begin{tabular}{l} 
Lower Risk \\
- Provide brief advice: "I \\
recommend that you stop \\
drinking, and now is the \\
best time. Your brain is still \\
developing, and alcohol can \\
affect that. Alcohol can also \\
keep you from making good \\
decisions and make you do \\
things you'll regret later. I \\
would hate to see alcohol \\
interfere with your future." \\
- Notice the good: Reinforce \\
any strengths and healthy \\
decisions. \\
- Explore and troubleshoot the \\
potential influence of friends \\
who drink or binge drink. \\
\hline
\end{tabular}

Moderate Risk
- Does the patient have
alcohol-related problems?
- If no, provide beefed-up
brief advice: Start with
the brief advice for Lower
Risk patients (at left) and
add your concern about the
frequency of drinking.
- If yes, conduct brief
motivational interviewing
to elicit a decision and
commitment to change
(see page 29 ).
Ask if parents know: See
suggestions for Highest Risk
patients (at right).
- Arrange for followup, ideally
within a month.

\section{FOR ALL PATIENTS WHO DRINK}

- Collaborate on a personal goal and action plan for your patient. Refer to page 31 for sample abstinence, cutting back, and contingency plans. For some patients, the goal will be accepting a referral to specialized treatment.

- Advise your patient not to drink and drive or ride in a car with an impaired driver.

- Plan a full psychosocial interview for the next visit if needed.

\section{Highest Risk}

- Conduct brief motivational interviewing to elicit a decision and commitment to change, whether or not you plan to refer (see page 29).

- Ask if parents know: If so, ask patient permission to share recommendations with them. If not, take into account the patient's age, the degree of acute risk posed, and other circumstances, and consider breaking confidentiality to engage parent(s) in follow-through.

- Consider referral for further evaluation or treatment based on your estimate of severity (see page 23).

- Arrange for followup within a month.

If you observe signs of acute danger, such as drinking and driving, high intake levels per occasion, or use of alcohol with other drugs, take immediate steps to ensure safety (see page 21). 


\title{
STEP 4: AT FOLLOWUP, CONTINUE SUPPORT
}

\author{
For patients who DID drink ...
}

It may be uncommon for patients to return for an alcohol-specific followup. Still, when patients with whom you've conducted an alcohol intervention return for any reason, you'll have an opportunity to strengthen the effects of the previous visit. Start by asking about current alcohol use and any associated problems. Then review the patient's goal(s) and assess whether he or she was able to meet and sustain them.

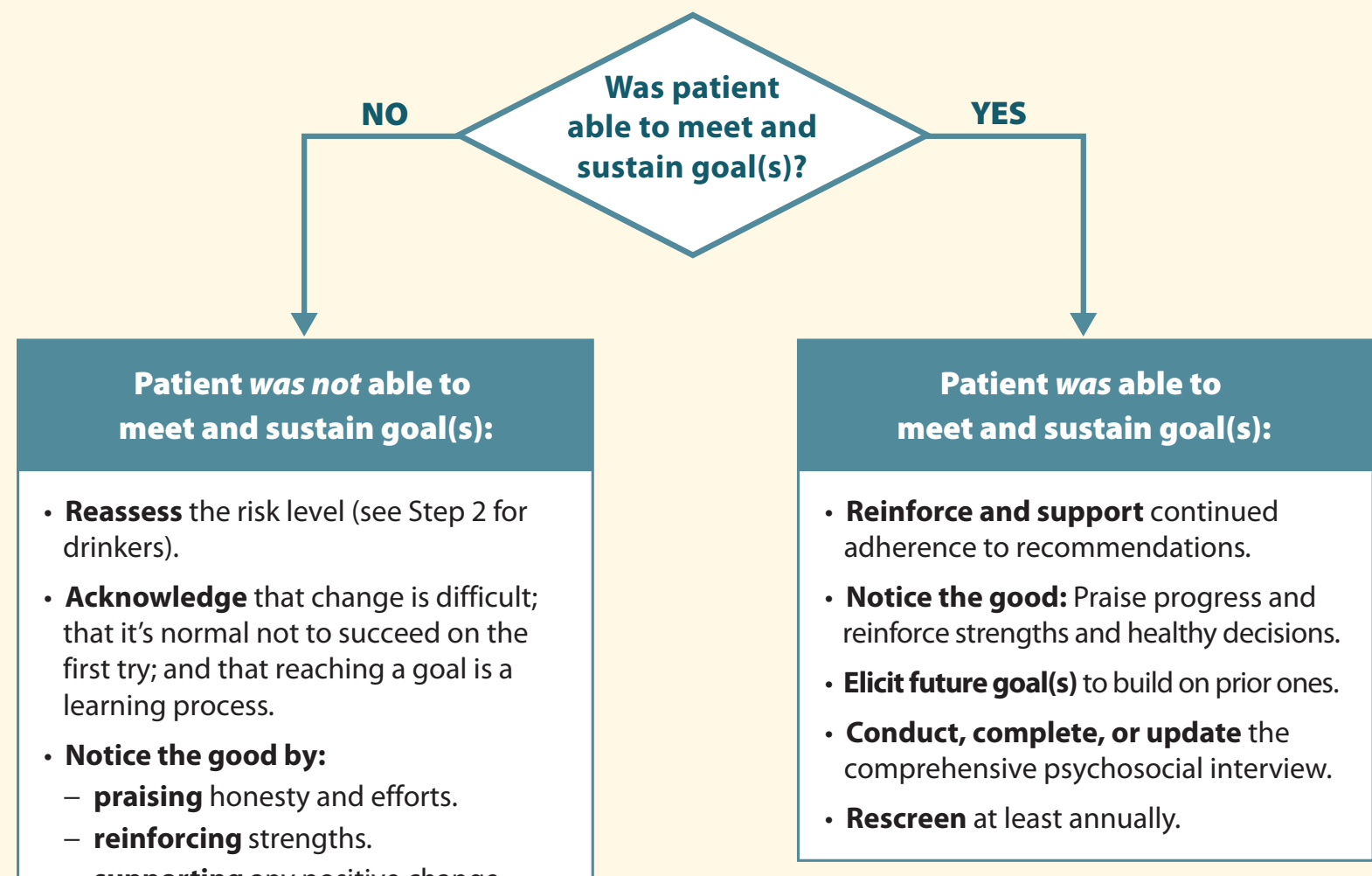

- supporting any positive change.

\section{- Relate drinking to associated consequences or problems to enhance motivation.}

- Identify and address challenges and opportunities in reaching the goal.

- If the following measures are not already under way, consider:

- engaging the parents.

- referring the patient for further evaluation.

- Reinforce the importance of the goal(s) and plan and renegotiate specific steps, as needed.

- Conduct, complete, or update the comprehensive psychosocial interview. 


\title{
APPENDIX
}

\author{
Frequently Asked Questions
}

About underage drinking patterns.................................................................14

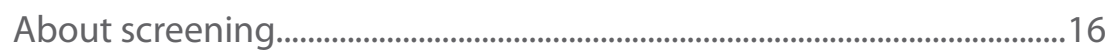

About guiding patients who do not drink and their parents.................18

About risk assessment ...........................................................................................19

About intervention .........................................................................................22

About office procedures ..................................................................................2

Clinician Support Materials

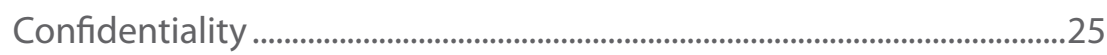

Brief motivational interviewing..................................................................2

Additional workup resources ............................................................................32

Referral resources ...............................................................................................

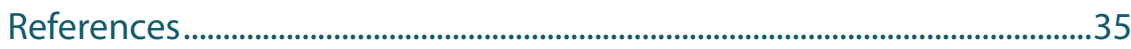

Additional Resources .........................................................................................38 


\section{FREQUENTLY ASKED QUESTIONS}

\section{About underage drinking patterns}

\section{At what age do kids start drinking?}

The average age at first drink is about 14 , according to national surveys of 12 - to 20 -year-olds (Chen et al., 2011). The more we can help kids delay when they begin drinking, the better, as the younger the age of drinking onset, the greater the chance for alcohol dependence later in life (Hingson et al., 2006; Grant \& Dawson, 1997).

\section{Do boys and girls differ in drinking patterns?}

Up to about 10th grade, the percentage of boys and girls who drink is about the same. By 12th grade, however, boys surpass girls, not only in terms of any use, but also in binge drinking and having been drunk in the past month (Johnston et al., 2010).

\section{How many kids in my practice are likely to screen positive for past-year drinking?}

As your patients get older, you're likely to see a dramatic climb in the number who drink. Although there will be regional and local variations, national surveys show that across adolescence, we can expect a tenfold rise in any past-year drinking (the measure that correlates with this Guide's screening questions) (NIAAA, 2011):

\section{Past-year drinking \\ (more than one or two sips) is reported by:}

1 in 15 12-year-olds

1 in 4 14-year-olds

1 in 2 16-year-olds

2 in 3 18-year-olds

\section{How much do kids drink?}

As kids get older, more drink and more drink heavily. In fact, you may find that dangerous binge drinking is quite common among your patients. National estimates for youth binge drinking currently use the binge definition for adult males, that is, five or more drinks per occasion. By that definition, among youth who drink, about half of those ages 12 to 15 and two-thirds of those ages 16 to 20 binge drank in the past 30 days (SAMHSA, 2010). These are likely underestimates, however, because the definition of binge drinking for most youth should be fewer drinks than for full-grown adult males (see next question). 


\title{
Having five or more drinks on at least one occasion in the past $\mathbf{3 0}$ days is reported by about:
}

\author{
Half of 12- to 15-year-olds who drink
}

Two-thirds of 16- to 20-year-olds who drink

\section{What's a "child-sized" or "teen-sized" binge?}

Compared with adults, children and teens are likely to have higher blood alcohol concentrations after drinking similar amounts of alcohol. Because we ethically cannot conduct clinical studies of youth drinking, we rely on mathematically derived estimates of blood alcohol levels for youth. Extrapolating from what is known about alcohol metabolism in adults, a recent study accounted for differences between adults and kids in body composition and alcohol elimination to estimate blood alcohol and binge levels for youth. The study concluded that binge drinking for youth should be defined as follows (Donovan, 2009):

\section{Estimated binge drinking levels for youth}

Ages 9-13

(See also the FAQ on page 20 on estimating your patient's quantity of drinking.)

\section{What kinds of alcohol are kids drinking these days?}

All kinds: beer, malt liquor, liquor, wine, and "flavored alcohol beverages." Generally similar to beer in percent alcohol, flavored alcohol beverages include wine coolers and sweetened maltbased drinks that often derive their alcohol content from spirits. Although we don't yet have a comprehensive, nationwide study on youth beverage choices, a few limited studies show that hard liquor is gaining on or overtaking beer and flavored alcohol beverages in popularity with youth and that wine is less preferred (Siegel et al., 2011; Johnston et al., 2010; CDC, 2007).

Young people are also drinking alcohol mixed with caffeine, either in premixed drinks or by adding liquor to energy drinks. With this dangerous combination, drinkers may feel somewhat less drunk than if they'd had alcohol alone, but they are just as impaired in motor coordination and visual reaction time (Ferreira et al., 2006). They are more likely to drink heavily, to be injured or taken advantage of sexually, and to ride with an intoxicated driver (O'Brien et al., 2008). 


\section{About screening}

\section{How effective are these screening questions?}

The new screening questions were empirically derived through analyses of data from (1) an 8-year span (2000-2007) of a nationally representative survey, which included more than 166,000 youth ages 12 to 18 (Smith et al., 2010) and (2) multiple longitudinal studies that collected information about young people as they grew up (Brown et al., 2010). While the two recommended questions have not yet been clinically tested, the analyses indicate that they are very effective predictors of adverse alcohol outcomes, both current and future. In addition, the questions are consistent with accepted standards of care in which youth are queried about friends' activities and personal health choices. (See also "What's the basis for the risk level estimates?" on page 19.)

\section{Is alcohol screening and brief intervention effective for youth?}

The evidence is clear that brief interventions are effective for adults. In fact, in 2004, the U.S. Preventive Services Task Force "recommended screening and behavioral counseling interventions to reduce alcohol misuse by adults" (USPSTF, 2004). At that time, the evidence was inconclusive about the effectiveness of alcohol brief interventions for adolescents.

Since then, however, evidence has been accumulating on the effectiveness of brief interventions for adolescents (Jensen et al., 2011; Tripodi et al., 2010; Walton et al., 2010). In addition, in its policy statement "Alcohol Use by Youth and Adolescents: A Pediatric Concern," the American Academy of Pediatrics recommends that clinicians who work with children and adolescents regularly screen for current alcohol use and use brief intervention techniques during office visits (AAP, 2010). (See also "Brief Motivational Interviewing," page 29.)

\section{Why are we asking about past-year drinking instead of past-month drinking, when we know kids have bad memories?}

All queries about past alcohol use are fallible in one way or another. Even so, responses to these queries can provide us with useful information about how children and adolescents are drinking. While data relating to past-month drinking may be more precise, data on past-year use helps to identify more youth who drink, since drinking by young people is often sporadic. When asked if they have had a drink in the past month, many youths may be able to answer "no" even though they have had alcohol at other times during the year. Additionally, research shows that responses on past-year use are predictive of alcohol-related problems (Smith et al., 2010). We ask children about their past-year use not because we know their answers are completely accurate, but because their responses can help predict symptoms and problems. 


\section{If I ask my patients how many times they drank in the past year, might this suggest to them that I expect them to drink?}

You can weave this Guide's screening questions into clinical interviews with your patients as you see fit. If you are concerned that kids may get the message that drinking is normative if you lead with a question about drinking frequency, then you might lead with a prescreener along the lines of "In the past year, have you had more than a few sips of beer, wine, or any drink containing alcohol?" For those who say yes, you can then ask, "On about how many days did you drink?" With a prescreening question, however, you may run the risk of getting a false "no" and bringing the screening to a stop. Use your sense of the individual patient's likelihood of alcohol involvement and your professional judgment to decide when to lead with a prescreener. In any case, if you praise a "no" response, patients will get the message that you don't find drinking at their age acceptable.

\section{What can I do to encourage my patients to give honest and accurate answers when I ask the screening questions?}

Establishing good rapport with patients is more of an art than a science. Below are suggestions for ways to encourage accurate responses and promote productive, trusting relationships:

- Build in alone time: Build in time during the visit for parents to leave the room so you can be alone with your patient to discuss potentially sensitive issues such as alcohol.

- Explain your confidentiality policy: Make sure your patient understands that unless he or she is danger, your conversation will remain between the two of you. You can discuss your confidentiality policy with parents and children together-both need to be familiar with it.

- Be on their side: Explain to your patients that you are not singling them out, but that you talk to all of your adolescent patients about alcohol use and other health risks. Your purpose is to keep all of your patients healthy and to offer good medical advice - not to get anyone in trouble.

\section{How do I prioritize screening for alcohol in relation to other risk behaviors such as unprotected sex, smoking, and use of other drugs?}

Alcohol use is an excellent place to start screening for risky health behaviors for two main reasons. First, talking with your patients about alcohol has the potential to save lives. Drinking is associated with three top causes of death among adolescents, the first being unintentional injury, usually by car crashes, followed by homicide and suicide (CDC, 2008).

Second, starting with questions about drinking can help you determine whether asking questions about other risk behaviors is a high priority. Alcohol is the drug used by the greatest number of adolescents (Johnston et al., 2010), and for many young people it is also the first substance they try. Youth who don't use alcohol are unlikely to use any other substances, whereas youth who are heavily involved with alcohol are at increased risk for using other substances and for other risktaking behaviors (NIAAA, 2011; Biglan et al., 2004). 


\section{Why should I bother screening kids that I'm almost positive aren't drinking alcohol?}

Talking about alcohol — with all of your patients — shows them that you care about their health and are concerned about the risks. You may be surprised to discover how widespread alcohol use really is among adolescents. Despite your best instincts, you will find that even "good kids" drink - and that their alcohol use can cause problems. Discussing alcohol with every adolescent who walks through your door helps make sure no one falls through the cracks.

For kids who are not drinking, this conversation offers you the opportunity to praise and encourage the smart and healthy choices they are making. We know that positive reinforcement works and this is a great opportunity to use it. In addition, research indicates that youth hold more positive perceptions of health care providers who bring up sensitive topics such as substance use, suggesting that young people may expect this standard of care (Brown \& Wissow, 2009).

\section{About guiding patients who do not drink and their parents}

\section{For younger patients who have not started to drink, what anticipatory guidance should I provide to patients and parents?}

For patients who are not drinking: Be sure to praise them for making the decision not to drink. Recommend that they get involved in activities that build on their strengths, choose friends who also make good choices, and avoid situations where alcohol or other drugs are easily available.

For their parents: Parents may wonder if allowing their children to drink with them in the home will help protect them from alcohol problems later in life. You can let them know that most studies indicate that the opposite is the case (McMorris et al., 2011; NIAAA, 2010) and that a permissive home environment can increase the odds for teen alcohol problems. Research suggests that parents who don't want their kids to drink do have an important influence over their kids' alcohol decisions, even through high school and the transition to college (Abar et al., 2009; Walls et al., 2009; Wood et al., 2004). Suggest that parents set clear expectations, such as making a house rule of no underage drinking, with equally clear and consistent consequences. Offer resources for learning about underage drinking (see page 38), and encourage parents to discuss the realities and consequences with their kids. Remind them that they can find many "teachable moments" about alcohol risks in the news and entertainment media. (See page 22 for handling a situation in which parents themselves have alcohol problems.)

\section{What parent educational materials or parenting Web sites can I suggest to families?}

See Additional Resources at the end of this Guide on page 38. 


\section{About risk assessment}

\section{What's the basis for the risk level estimates?}

The risk level estimates in this Guide - and the screening question on drinking frequency - come from analyses of national survey data on alcohol use by more than 166,000 youth ages 12 to 18 (Smith et al., 2010). Researchers looked for connections between drinking pattern variables and concurrent symptoms of an alcohol use disorder (AUD), whether alcohol abuse or dependence, as defined in the Diagnostic and Statistical Manual of Mental Disorders, Fourth Edition, published by the American Psychiatric Association.

Consistently, they found that the number of drinking days in the past year predicted the presence of AUD symptoms more accurately than the quantity of alcohol consumed or the frequency of binge drinking. It's important to note your patients do not need to be completely accurate when estimating past-year drinking, because the reported frequency predicts the presence of AUD symptoms.

\section{Among my patients who drink, what proportion will be in the "lower," "moderate," and “highest" risk categories?}

National data provide the big picture, which will vary somewhat by region. At ages 12 to 15 years, any drinking is considered at least "moderate" risk, and half of drinkers in this age group drink frequently enough to be in the "highest risk" category. At ages 16 to 18, about one-third of drinkers are at "lower risk," one-fifth at "moderate risk," and just under half are at "highest" risk (NIAAA, 2011).

Approximate distribution of young drinkers at lower, moderate, and highest risk levels

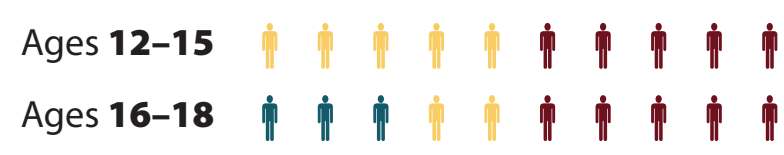

\section{How can I remember the cut points for the different risk levels?}

When you're getting started, you can use the Pocket Guide (enclosed), which contains the risk estimator chart. Over time, you will get a feel for the risk cut points for the different ages and the correlated intervention levels. To facilitate that process, you might focus first on the "highest risk" cut points, which identify the kids who need the most attention and possibly a referral.

\section{Highest risk past-year drinking begins at:}

Age 11: 1 day

Ages 12-15: 6 days (about every other month)

Age 16: 12 days (about monthly)

Age 17: 24 days (about twice monthly)

Age 18: $\mathbf{5 2}$ days (about weekly) 
Once those become familiar, you can round out the picture with the cut points for "moderate risk":

\section{Moderate risk past-year drinking begins at:}

Ages 12-15: 1 day

Ages 16-17: 6 days (about every other month)

Age 18: 12 days (about monthly)

Again, these risk levels and cut points are not absolutes, but instead indicators to help you gauge the extent of your professional response.

\section{As part of the risk assessment, how can my patient and I estimate drink quantities?}

That can be a challenge. Some youth drinking choices are easier to quantify (shots, cans, bottles, and beer from a keg served in 16-ounce plastic cups), whereas others are inventive, built for speed, and harder to measure (such as gelatin shots and beer chugged from funnels called beer bongs).

Fortunately, with this Guide, you don't need precise quantity estimates to gauge your patient's risk because the number of drinking days in the past year is a powerful predictor of risk on its own. Still, for moderate and highest risk drinkers, you will want to ask about quantity of drinking to round out your risk assessment.

For some perspective, the tables below provide information about "standard drink" sizes and the approximate number of standard drinks in common containers for beverages with different amounts of alcohol by volume (or alc/vol). (For more information, visit www.RethinkingDrinking.niaaa.nih.gov.)

\section{What counts as a drink?}

Many people are surprised to learn what counts as a drink. In the United States, a "standard" drink is any drink that contains about 0.6 fluid ounce or 14 grams of "pure" alcohol. Although the drinks below are different sizes, each contains approximately the same amount of alcohol and counts as a single standard drink.

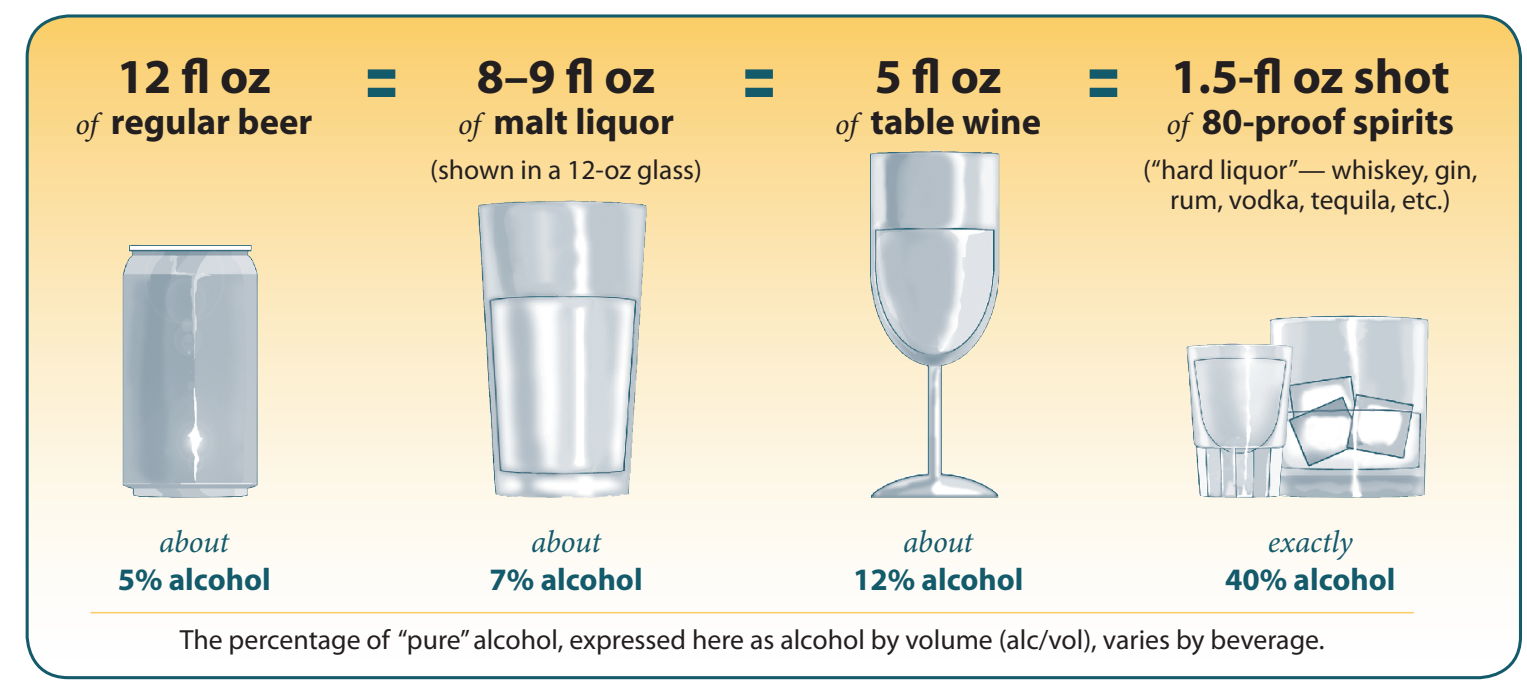




\section{How many drinks are in common containers?}

Below is the approximate number of standard drinks in different-sized containers of:

\begin{tabular}{|c|c|c|c|}
\hline regular beer & malt liquor & table wine & $\begin{array}{l}\text { 80-proof spirits } \\
\text { or "hard liquor" }\end{array}$ \\
\hline $12 \mathrm{floz}=1$ & $12 \mathrm{floz}=\mathbf{1 . 5}$ & 5 -fl oz glass $=1$ & a shot $(1.5 \mathrm{oz})=\mathbf{1}$ \\
\hline $16 \mathrm{floz}=1.3$ & $16 \mathrm{floz}=2$ & $25 \mathrm{floz} \quad=5$ & $750 \mathrm{ml}(a$ "fifth") = 17 \\
\hline $40 \mathrm{floz}=3.3$ & $40 \mathrm{floz}=4.5$ & $\begin{array}{l}\text { (a regular } \\
750-\mathrm{ml} \text { bottle) }\end{array}$ & $1.75 \mathrm{~L}\left(a^{\text {"handle" })=39}\right.$ \\
\hline
\end{tabular}

These examples are a starting point for comparison. Alcohol content can vary greatly across different types of beer, malt liquor, and wine. "Flavored alcohol beverages" or "alcopops" have a particularly wide range, from about 5 percent to 12 percent alc/vol. For other beverages, the differences may be smaller than you might expect. The most popular light beers, for example, have almost as much alcohol as regular beer.

\section{What do you mean by "incorporate what else I know" about my patient and his or her family in my risk assessment and intervention?}

Your awareness of family factors such as these would heighten concern about the degree of risk:

- A history of alcohol problems in parents or siblings

- Divorce or other challenging transition

- Low parental involvement in kids' lives

- Kids who have too much unsupervised time or say they're "bored"

In addition, details you may already know about your patient's strengths, interests, and health conditions can help personalize and strengthen your intervention messages. For example:

- Athletes or scholars who drink could compromise their performance in sports or academics and, in schools with zero tolerance policies, be kicked off teams or clubs if caught drinking even once.

- Kids with chronic conditions such as diabetes, anxiety, or depression can complicate management of their conditions by drinking.

\section{What are "acute danger signs"—-behaviors so potentially dangerous that they require a "highest risk" intervention on the spot?}

The most common and potentially lethal danger sign is drinking and driving. Unless a patient who drinks and drives commits to stopping, an immediate intervention is warranted. This can include informing the patient's parents, recommending that they take away car keys and driving privileges, and referring the patient for treatment. 
Besides drinking and driving, other signs of acute danger that indicate a "highest risk" intervention and probable referral include:

- High, potentially lethal volume intake

- Combining alcohol with other drugs, especially sedatives

- Substance-related hospital visits or injuries; alcohol poisoning

- Unplanned or unprotected sexual activity associated with alcohol use

- Signs of alcohol addiction; drinking daily or near-daily; having memory blackouts

- Use of intravenous drugs

\section{About intervention}

See also the summary of "Brief Motivational Interviewing" on page 29.

\section{What should I do if my patient says, "I'm not going to stop"?}

There are several ways you can choose to handle a negative response.

For kids who seem at relatively lower risk, you can ask permission to give brief advice, provide the advice if accepted, and ask what they make of it. For example, you might say: "You ultimately make the decision, but at the same time, I recommend that you don't drink alcohol at all. You are a good [student, athlete, sibling, friend]; I would hate to see alcohol get in the way of your future and the things you care about. What do you think?" For those who decline the advice, suggest that they think about your conversation a bit more.

For kids who are at moderate or highest risk, motivational interviewing should be helpful. For example, you might say: "I understand you recently had a blackout from drinking too much and your parents were very upset. You agree that you drank too much that night, and that was dangerous and a little scary. How do you want to move forward?" Consider setting up a followup appointment, as just one additional session of motivational interviewing can make a difference. In some cases, you may need to break confidentiality and inform the patient's parents. In others, you might suggest a referral to a counselor.

\section{What, if anything, should I do differently if I know that one or both of my patient's parents have alcohol-related problems?}

Though a minority, the youth in your practice whose parents have an alcohol use disorder are among those at the greatest risk. How you decide to approach this issue will depend on your assessment of the extent of the parental problems. If you sense that one parent would be an ally, then referring that parent to an expert for help in dealing with family drinking problems would be appropriate and advisable.

If, however, both parents appear to be heavy drinkers or dependent on alcohol, your concern may be better expressed generically. As an example: "Justin is at an age when all parents need to be concerned about their children's alcohol use. Kids this age often do not even know when they are in a dangerous situation. Of course, how much their friends drink is usually a big influence. But many people aren't aware that the amount of drinking by family members and the easy availability of alcohol in the home may make it more difficult for their child to know how to manage when risky drinking situations occur. For this reason, I ask that families be open to the possibility that expert advice may be useful in keeping their children safe. We have some good resources available. May I make that connection for you? What are your thoughts about a referral?" 
In these circumstances, even if the offer of help is refused, it is important for health care providers to make a point at each visit of expressing concern, with a focus on both the risk-taking behaviors and the specific vulnerabilities of the child's developmental stage.

\section{Should I recommend any particular specialty treatment for patients who need referrals?}

One size doesn't fit all when it comes to alcohol treatment options. Fortunately, a range of effective treatment choices is available. A recent meta-analysis found that several types of substance abuse treatment can reduce adolescent alcohol abuse (Tripodi, 2010), including individual-only and family-based interventions. In contrast to earlier meta-analyses, this study generally found larger effect sizes in individual over family-based interventions. Either can be effective, however, so the authors caution against unequivocally recommending individual therapy over family-based at this point.

Of note, the analysis found that three of the therapies with large effect sizes included brief interventions. Among the longer-term treatments with larger effect sizes were cognitivebehavioral therapy integrated with a 12-step approach, cognitive-behavioral therapy with aftercare, and multidimensional family therapy. Also found effective, with medium effect sizes, were integrated family and cognitive behavioral therapy, behavioral treatment, and triple modality social learning.

For suggestions on how to find adolescent substance abuse specialists and programs in your area, see Referral Resources, page 34. It is a good idea to develop working relationships with local resources and practitioners, so you can make solid, confident recommendations and provide a continuity of care.

\section{How can I help a patient who struggles to remain abstinent or who relapses?}

Changing drinking behavior is a challenge, especially for patients who are alcohol dependent. Although you will have referred alcohol-dependent patients to specialty treatment, of course you will still see them for other visits. If you learn that a patient has relapsed, recognize that he or she may have developed a chronic disorder that requires continuing care, just like asthma or diabetes. The most important principle is to stay engaged with the patient and to maintain optimism about eventual improvement. In addition:

- If the patient objected to the initial referral, seek another appropriate, acceptable option.

- Assess and address possible triggers for struggle or relapse, including stressful events, interpersonal conflict, insomnia, chronic pain, or high-temptation situations.

- Address depression, anxiety disorders, or conduct problems, referring to specialty treatment if needed.

- Point out any progress while noting the difficulty and multi-step nature of making a change (see also Step 4, page 12).

Depending on the family situation, you might also encourage family members to participate in mutual support groups such as Al-Anon. Continue to collaborate with the family and any treatment providers as the recovery process continues. 


\section{About office procedures}

\section{How can a clinic- or office-based screening system be implemented?}

One option is to allow patients to fill out a pen-and-pencil or computer-based questionnaire either in the waiting room or prior to the visit, as long as they have privacy to do so. Another is for the health care provider, preferably one who knows the patient well, to ask the questions during office visits. A third is for other clinical personnel to screen patients during check-in. If a clinical assistant will screen patients instead of the primary health care provider, be sure to work out record-keeping to facilitate followup in the exam room.

For further guidance, see the American Academy of Pediatrics' new manual on implementing mental health screenings called Addressing Mental Health Concerns in Primary Care: A Clinician's Toolkit. Included in the Toolkit is a readiness to screen checklist and suggestions on how to prepare the office staff. You can access these materials at www.aap.org/mentalhealth.

\section{Can I be reimbursed for conducting alcohol screening and brief intervention?}

Progress has been made in recent years, such that with proper coding it's now possible to be reimbursed for alcohol screening and brief intervention. See the latest AAP publication Coding for Pediatrics for up-to-date, detailed information (AAP, 2011). Two caveats: Check with your patients' insurers, as some companies reimburse only mental health care providers for substance use diagnoses. In addition, if you are treating a patient without the parent's knowledge, be aware that confidentiality will be compromised if diagnostic codes are included in explanations of benefits sent to a parent. 


\section{CONFIDENTIALITY}

Confidentiality often plays a role in providing health care to adolescents. When it comes to alcohol use by patients who are minors, don't let concerns about confidentiality deter you from screening and intervening as needed. All of the major medical organizations and numerous current laws support the ability of clinicians to provide confidential health care, within established guidelines, for adolescents who use alcohol (Berlan \& Bravender, 2009; Ford et al., 2004).

It is important to give your patients an assurance of confidential care. Studies show that with confidentiality assurance, adolescents are more willing to seek health care (Ford et al., 1997), whereas without it, those who engage in risky behaviors will often forego care (Lehrer et al., 2007). In addition, research indicates that most parents favor confidential care for their teens, and that education about privacy policies and teen risk-taking behaviors improves the opinions of most parents who hold negative opinions about confidentiality (Hutchinson \& Stafford, 2005).

This section provides a brief overview of patient rights and professional association guidance, along with practical suggestions for screening adolescent patients for alcohol use while respecting confidentiality and its limitations.

\section{Patient rights}

State laws govern minor patient rights to confidentiality of information shared with health care providers about alcohol and drug use. Across States, laws vary on provisions, including the definition of a minor (typically under age 18), the ability of a minor to consent to substance abuse treatment, parental notification of treatment, and the disclosure of medical records. It is important to be aware of specific laws in your State, which generally allow health care practitioners to use professional judgment in determining the limits of confidentiality. For information about your State's laws, contact your State medical society. In addition, a summary of State minor consent laws, including confidentiality and disclosure provisions, is available from the Center for Adolescent Health and the Law (English et al., 2010; www.cahl.org).

Federal medical privacy rules established by the Health Insurance Portability and Accountability Act (HIPAA) allow adolescent health care providers to "honor their ethical obligations to maintain confidentiality consistent with other laws" (Ford et al., 2004). For example, HIPAA only allows parents to have access to the medical records of a minor child if that access does not conflict with a State or other confidentiality law. If State or other laws are silent on this matter, clinicians can exercise professional judgment in deciding whether to allow access (Ford et al., 2004).

Additionally, federally funded treatment centers are subject to the Code of Federal Regulations (42 CFR Part 2), which offers different guidance from HIPAA. These regulations protect the confidentiality of records on alcohol and drug use of minor patients. These records cannot be shared with anyone - including a parent or legal guardian — without written consent of the minor patient. 


\section{Professional association guidance}

Professional associations have produced helpful guidelines, policies, and background information to help steer you through the complex framework of laws and issues related to minor consent, privacy, and confidentiality. A sampling of guidance from several organizations is offered below; visit your member association Web site(s) for the full picture, or visit the Center for Adolescent Health and the Law Web site (www.cahl.org) for a policy compendium (Morreale et al., 2005).

"The most useful information will be obtained in an atmosphere of mutual trust and comfort," states the American Academy of Pediatrics (Kulig \& AAP Committee on Substance Abuse, 2005). To facilitate confidential care, the AAP recommends establishing a privacy policy and sharing it with parents and children around the time of the 7- or 8-year-old checkup, or at least by the 9- or 10-year-old checkup (Hagan et al., 2008). Also around this time, and certainly by the 12-year-old checkup, you should routinely set aside a portion of the visit to spend time alone with the patient (Hagan et al., 2008). This sets the stage for regular private conversations between adolescents and clinicians throughout the second decade.

Regarding the central question of how to involve parents in your patients' care, the American Academy of Family Physicians (AAFP) advises health care providers to make a "reasonable effort to encourage the adolescent to include parents or legal guardians in health-related decisions" (AAFP, 2008). If you do not think parent involvement would be beneficial, however, the American Medical Association (AMA) advises that "parental consent or notification should not be a barrier to care" (AMA, Policy H-60.965). The Society for Adolescent Health and Medicine (SAHM) concurs, stating that "participation of parents in the health care of their adolescents should be encouraged, but should not be mandated" (Ford et al., 2004).

Of course, there will be times when you'll need to consider breaking confidentiality and involving parents (see page 28, "When is it appropriate to break confidentiality?"). As summarized by the AAFP, "Ultimately, the judgment of the physician should prevail in the best medical interest of the patient" (AAFP, 2008).

\section{Practical recommendations}

- Always explain your confidentiality policy: It can be very effective to explain your practice's confidentiality policy to both the patient and the parent at the same time. For example:

- Direct to patient: "I will be asking you some personal questions that I ask all of my patients so I can take the very best possible care of them. Everything we say here will be confidential, in other words, will stay between you and me, but within certain limits. The exception is if you tell me someone is hurting you physically or sexually, or if you are hurting or planning to hurt yourself or someone else, then we will have to tell others and get them involved to help keep you or the other person safe."

- Direct to parent: "What your daughter/son says to me is confidential, but obviously you are free to discuss any topics between yourselves at any time. If your daughter/ son is in immediate danger or needs further treatment, I will certainly inform you and include you in any discussions." 
- Establish private time for screening: If you offer a paper or electronic screening tool before the exam, then clearly communicate to the patient and parent that privacy is needed to complete the screen. If you ask the screening questions yourself, only do so when parents are not in the room. Because the initial screening sets the stage for later visits, establish private time, starting with the first screening. This way, you'll avoid sending a message that you would disclose the content of these conversations to the parent in the future.

- Establish private time for talking: It is important to establish a standard routine for adolescent patients to spend part of each visit alone with the clinician. Typically, the visit starts with both patient and parent present, then the clinician spends time privately with the patient, and the end of the visit serves as a group wrap-up. The rationale for private time is both developmental (that is, acknowledging the patient's emerging autonomy and encouraging him or her to acquire skills to get health needs met) as well as to encourage open communication about sensitive health issues. In deciding when to establish private time for a given patient, take more than just the patient's age into account. A physically mature or provocatively dressed 10-year-old, for example, may be more in need of an alcohol screen than some of your older patients.

- Decide how and when to honor commitments to change: A key intervention goal for patients who have begun drinking but are not in acute danger is to obtain a commitment to stop or cut back drinking. With older adolescents, it is often best to maintain confidentiality (if requested) after accepting the patient's commitment to avoid risky behaviors. If your patient refuses to commit, however, or if you doubt the sincerity of the commitment, you may want to consider breaking confidentiality. Furthermore, if at followup visits you find that a patient has not demonstrated a commitment to the agreed-upon plan or has escalated his or her use, you should also consider breaking confidentiality. This can be framed within a context of concern for the patient's health and the need to get a trusted adult involved to facilitate getting the help or treatment the patient needs.

- Keep followup visits confidential: You can maintain confidentiality even if your patient's alcohol use indicates the need for a followup visit. Many physicians schedule the next appointment with a medical "hook," such as the need to follow up for acne or an immunization or to discuss medications or lab results.

- Talk about referrals: If you need to refer patients for further treatment, you may need to talk to them about breaking confidentiality to discuss the referral with their parents. This may be relatively simple, because in most cases when your patient is drinking enough to require a referral, the parents are already aware that their son or daughter is drinking.

- Be aware of practice procedures that can break confidentiality inadvertently: These may include appointment reminders and billing and reimbursement procedures. The SAHM advises you to develop strategies to "provide appropriate confidential care within this context where feasible" (Ford et al., 2004). Consider taking continuing education courses that not only keep you abreast of confidentiality matters in general but also touch on issues that may arise as electronic medical records become more prevalent. 
- Clarify risks of releasing medical records to parents: It is unusual for a parent to demand access to a child's medical record without first trying to get answers from the child or health care provider. On the chance that a parent does request medical records containing confidential information, it's important to know your State's laws about release. Typically, minors should be able to control access to information about services for which they can legally provide consent, such as alcohol use and treatment in many States. If you are not able to protect the release of medical records, then it's important to make it clear, prior to release, that by reading any sensitive health information, the parent may compromise your rapport and ability to work with the child. It may make it more difficult to elicit honest and accurate information from your patient, who will have lost trust in you. Suggest that the parent reconsider the request.

\section{When is it appropriate to break confidentiality?}

Your clinical judgment, together with your State's minor consent laws, holds the answer. Below are general guidelines related to age levels and alcohol use. In addition, consider the reported alcohol-related behaviors and associated risks of significant injury, as well as the presence and seriousness of any co-morbid conditions (such as depression, risk of suicide, poorly controlled insulin-dependent diabetes).

\begin{tabular}{|c|c|c|c|}
\hline & $\begin{array}{l}\text { Any Alcohol } \\
\text { Use }\end{array}$ & $\begin{array}{l}\text { Some Mild } \\
\text { Problems }\end{array}$ & $\begin{array}{c}\text { Significant Problems } \\
\text { or Probable } \\
\text { Dependence }\end{array}$ \\
\hline $\begin{array}{r}\text { Elementary School } \\
\text { (ages 9-11) }\end{array}$ & Yes & Yes & Yes \\
\hline $\begin{array}{l}\text { Middle School } \\
\text { (ages 11-14) }\end{array}$ & Maybe & Yes & Yes \\
\hline $\begin{array}{l}\text { High School } \\
\text { (ages 14-18) }\end{array}$ & Maybe & Maybe & Yes \\
\hline
\end{tabular}




\section{BRIEF MOTIVATIONAL INTERVIEWING}

Given the time constraints of your busy practice, you may wonder about quick and effective ways to help children and teens adopt healthier behaviors. If it's not already in your repertoire, consider adding brief motivational interviewing, a patient-centered communication style designed to enhance a patient's own motivation to change.

\section{What is motivation?}

Over the past few decades, advances in behavior research and theory propelled a major shift in the concept of motivation (Tevyaw \& Monti, 2004). It is no longer considered an all-or-nothing, unchanging character trait in which an individual is either motivated or not. Instead, motivation is viewed as a dynamic state of "readiness to change" that can be influenced by interpersonal interactions, with confrontation leading to resistance, and with understanding and empathy leading to change (Tevyaw \& Monti, 2004; Levy et al., 2002).

How do people move forward in the change process? According to behavior researchers, they become motivated when they "perceive a discrepancy between where they are and where they want to be" (Miller et al., 1992). As a trusted health care provider, you are in a prime position to help your patients recognize the disconnect between their behavior and their goals, values, and beliefs, and to make a change for the better.

\section{What is motivational interviewing?}

Motivational interviewing is a directive, patient-centered style of counseling that helps patients explore their natural ambivalence about changing. Its friendly, collaborative "spirit" is considered more important than any particular set of techniques. The broad goal is to elicit motivation from within the patient, not impose it from without. A core task is to help patients examine their own reasons for and against making a change, and then guide them to a resolution that triggers change in a healthy direction. Once patients commit to a change, they may or may not need further assistance as to how to make the change - where there is a will, there are many ways (Rollnick \& Miller, 1995).

Although this counseling style grew out of the substance abuse field, motivational interviewing is now used to address many other health behaviors, such as medication compliance and dietary control (Erikson et al., 2005; Rubak et al., 2005). Thus, you may find that skills development in this area will serve you well for any patient behavior change you would like to facilitate.

\section{How is it done?}

There is no single prescribed way to do motivational interviewing; each interaction will be as individual as the particular patient and his or her perspectives, goals, values, and beliefs. At its core, however, four basic principles underlie the approach (Miller et al., 1992):

Express Empathy: Take a warm, nonjudgmental stance; listen actively and reflect back on what is said to help the patient feel heard.

Develop Discrepancy: Raise awareness of the patient's personal consequences of drinking; ask how his or her goals, values, or beliefs could be hindered or compromised by drinking. 
Roll with Resistance: Acknowledge the patient's beliefs and feelings; avoid lecturing or debating; change gears and affirm autonomy if the patient shows resistance.

Support Self-efficacy: Express confidence in the patient's ability to make a change; point to patient's strengths and other successes as examples.

As with most skills, proficiency in motivational interviewing increases with a combination of training, practice, and feedback. For more background about motivational interviewing, along with information about workshops and coaching, visit www.motivationalinterview.org or www.motivationalinterview.net. You may also wish to refer to the book and journal articles referenced in this section.

\section{Versatile and tailor-made for teens}

You can apply motivational interviewing to address any level of alcohol use in your patients, from a first, isolated experience to regular, heavy, problematic drinking (Narr-King \& Suarez, 2011; Tevyaw \& Monti, 2004; Levy et al., 2002). It can be especially useful for adolescents in the early stages of readiness to change, whether they are not yet interested in changing or they are thinking about it, but are not yet ready to commit (Gold \& Kokotailo, 2007). Patients who present with a drinking-related injury or other negative consequence may be especially receptive in that painful "teachable moment" (Macgowan \& Engle, 2010). Even for patients with alcohol dependence, motivational interviewing can encourage the patient to accept a referral to specialty treatment (Levy et al., 2002) and engage more fully in care.

Though initially developed for adults, motivational interviewing is especially well suited for adolescents. It avoids confrontation, which allows the adolescents their individuality. Its open and respectful exchange of views supports teens' desire to have their viewpoints heard and their quest for autonomy. It can have benefits even when a patient does not admit to having a problem (Tevyaw \& Monti, 2004), which is often the case. When patients aren't ready to commit to a behavior change, motivational interviewing allows you to maintain rapport by "meeting them where they are" in their change process and negotiating for some interim steps. In the process, as you elicit and show that you value their opinions, teen patients get the opportunity to demonstrate their often remarkable resourcefulness and to build decision-making skills that will serve them well into adulthood.

\section{How effective is it?}

In adults, the effectiveness of brief motivational interviewing has been well established. A meta-analysis of 72 randomized controlled trials (RCTs) found that motivational enhancement interventions outperformed traditional advice for a range of health behaviors in 8 out of 10 studies (Rubak et al., 2005). Brief motivational interviewing can be effective in single visits as short as 15 minutes, and adding one or more followup visits nearly "ensures" effectiveness (Rubak et al., 2005). Alcohol-focused studies have shown that motivational enhancement and other brief interventions can reduce heavy drinking in nondependent adults, often as well as more intensive treatment (Tevyaw \& Monti, 2004).

In adolescents, studies of brief motivational interviewing for alcohol interventions thus far are limited, but show promise (Macgowen \& Engle, 2010). A 2010 review of 14 RCTs of brief alcohol interventions for adolescents in clinical settings indicated that motivational interviewing appeared more successful than other types of interventions and that even a single session can have positive effects (Wachtel \& Staniford, 2010). A 2011 meta-analysis also supported the effectiveness of motivational interviewing interventions for adolescent substance use (Jensen et al., 2011). 
Thus, the combination of solid evidence in adults and promising results in adolescents makes motivational interviewing arguably the most reasonable, as well as the most feasible, approach to recommend at this time for brief interventions with adolescents in clinical settings

(Clark et al., 2010).

\section{Setting individual goals and action plans}

With youth who drink alcohol, setting goals and action plans in the course of motivational interviewing is trickier than it is with adults. Motivational interviewing involves encouraging a patient's autonomy in choosing his or her course of action, as well as acknowledging and complimenting any change in a positive direction. People under age 21 who drink alcohol, however, legally do not have complete freedom of choice when it comes to drinking decisions. The goals you and your patient set need to be discussed in the context of both the patient's safety and restrictions imposed by the law, parents, school, or other sources (Tevyaw \& Monti, 2004).

Your assessment (page 10) will help direct and shape the individual goals for your patient related to drinking. Abstinence would, of course, be the ideal goal for youth who drink. In many cases, however, cutting back and taking other steps to avoid harm are more realistic and achievable goals. For dependent and other higher risk patients, the goal will be accepting a referral to specialized treatment.

The following sample action plans for youth who drink but are not dependent can help you and your patient chart constructive courses (adapted from Levy et al., 2002):

- Abstinence challenge: Ask permission from the adolescent to make a contract for 4-8 weeks of abstinence to help the two of you determine the severity of the problem. Discuss ways to successfully avoid drinking. At followup, reinforce success and discuss referral for more extensive assessment for those who failed the challenge or found it very stressful.

- Cut back: For those who refuse to abstain, ask permission to negotiate and contract for drinking limits based on the patient's history. In general, advise no substance use on weeknights, reducing quantity, and avoiding dangerous situations, such as drinking and driving. Elicit feedback from patients about your suggestions. At followup, continue to develop discrepancies and ask what additional steps they wish to take to reach their goals, building on prior successes.

- Contingency: For more challenging or resistant patients who refuse even to cut back, see treatment as a process and accept any progress, such as discussing perspectives on their drinking, as partial success. Create a list of contingencies that indicate that a problem exists, and ask patients to agree to come see you if they occur. Avoid arguments, roll with resistance, and encourage them to continue thinking about their drinking and continue self-monitoring.

\section{Followup}

In general, followup is necessary. Negotiating a time frame for followup with the patient may enhance the likelihood that the patient returns. As noted by the American Academy of Pediatrics, sometimes a medical "hook" (e.g., a followup for acne or an immunization or to discuss lab results) can bring the patient back to your office (AAP Adolescent Health Update Editorial Board, 2007). Studies indicate that just one additional visit can significantly improve the effectiveness of your intervention (Rubak et al., 2005). 


\section{ADDITIONAL WORKUP RESOURCES}

Using the quick two-question screening tool and risk level estimates in this Guide, you'll have a good idea as to your patients' level of risk for alcohol-related problems. You can further gauge the risk level and need for referral by asking more questions, as suggested on page 10, by using a formal tool, or both.

Two short tools to consider are the Alcohol Use Disorders Identification Test (AUDIT), which delves more deeply into alcohol-related behaviors, and the CRAFFT, explained below, which inquires about other drug use in addition to alcohol use. Both the AUDIT and the CRAFFT can be used as a paper-pencil or electronic screen, and the CRAFFT can be verbally administered. Both identify problems that can be discussed during motivational interviewing. And both should, of course, be administered with patient privacy protected.

The 10-question AUDIT instrument, available on the next page, was designed for use with adults and may be appropriate for adolescents, as well (Reinert \& Allen, 2007). The AUDIT's validity has been consistently confirmed in adults (Reinert \& Allen, 2007). Research also supports use of the AUDIT for adolescents ages 14 to 18, with lower cut points of 2 for identifying any alcohol problem use and 3 for alcohol abuse or dependence (Knight et al., 2003).

You may be familiar with the CRAFFT tool, which is incorporated into the American Association of Pediatrics Policy Statement on Substance Use Screening, Brief Intervention, and Referral to Treatment for Pediatricians (AAP Committee on Substance Abuse, in press). The CRAFFT identifies adolescent alcohol and drug use and associated behaviors. Research indicates that a "yes" to two of the questions below signals a problem needing further evaluation and that a score of 4 or more "should raise suspicion of substance dependence" (Knight et al., 2002):

C: Have you ever ridden in a CAR driven by someone (including yourself) who was "high" or had been using alcohol or drugs?

R: Do you ever use alcohol or drugs to RELAX, feel better about yourself, or fit in?

A: Do you ever use alcohol or drugs while you are by yourself, ALONE?

F: Do you ever FORGET things you did while using alcohol or drugs?

F: Do your family or FRIENDS ever tell you that you should cut down on your drinking or drug use?

T: Have you ever gotten into TROUBLE while you were using alcohol or drugs?

Along with the two-question screener in this Guide, these tools fit well with broader based, structured psychosocial interview schemes such as the HEADSS (questions about home, education, activities, drug and alcohol use, sexuality, and suicide) and interviews that add a focus on strengths that may help offset risks. The American Academy of Pediatrics notes: "Structured tools can be easily incorporated into the written or electronic health record to remind the practitioner to conduct screening and document the results" (AAP Committee on Substance Abuse, in press). 
PATIENT: Because alcohol use can affect your health and can interfere with certain medications and treatments, it is important that we ask some questions about your use of alcohol. Your answers will remain confidential, so please be honest.

Place an $\mathrm{X}$ in one box that best describes your answer to each question.

\begin{tabular}{|c|c|c|c|c|c|}
\hline Questions & $\mathbf{0}$ & 1 & 2 & 3 & 4 \\
\hline $\begin{array}{l}\text { 1. How often do you have a drink } \\
\text { containing alcohol? }\end{array}$ & Never & $\begin{array}{l}\text { Monthly } \\
\text { or less }\end{array}$ & $\begin{array}{l}2 \text { to } 4 \\
\text { times a } \\
\text { month }\end{array}$ & $\begin{array}{l}2 \text { to } 3 \\
\text { times a } \\
\text { week }\end{array}$ & $\begin{array}{l}4 \text { or more } \\
\text { times a } \\
\text { week }\end{array}$ \\
\hline $\begin{array}{l}\text { 2. How many drinks containing } \\
\text { alcohol do you have on a typical } \\
\text { day when you are drinking? }\end{array}$ & 1 or 2 & 3 or 4 & 5 or 6 & 7 to 9 & 10 or more \\
\hline $\begin{array}{l}\text { 3. How often do you have } 5 \text { or more } \\
\text { drinks on one occasion? }\end{array}$ & Never & $\begin{array}{l}\text { Less than } \\
\text { monthly }\end{array}$ & Monthly & Weekly & $\begin{array}{l}\text { Daily or } \\
\text { almost daily }\end{array}$ \\
\hline $\begin{array}{l}\text { 4. How often during the last year } \\
\text { have you found that you were } \\
\text { not able to stop drinking once } \\
\text { you had started? }\end{array}$ & Never & $\begin{array}{l}\text { Less than } \\
\text { monthly }\end{array}$ & Monthly & Weekly & $\begin{array}{l}\text { Daily or } \\
\text { almost daily }\end{array}$ \\
\hline $\begin{array}{l}\text { 5. How often during the last year } \\
\text { have you failed to do what } \\
\text { was normally expected of you } \\
\text { because of drinking? }\end{array}$ & Never & $\begin{array}{l}\text { Less than } \\
\text { monthly }\end{array}$ & Monthly & Weekly & $\begin{array}{l}\text { Daily or } \\
\text { almost daily }\end{array}$ \\
\hline $\begin{array}{l}\text { 6. How often during the last year } \\
\text { have you needed a first drink in } \\
\text { the morning to get yourself going } \\
\text { after a heavy drinking session? }\end{array}$ & Never & $\begin{array}{l}\text { Less than } \\
\text { monthly }\end{array}$ & Monthly & Weekly & $\begin{array}{l}\text { Daily or } \\
\text { almost daily }\end{array}$ \\
\hline $\begin{array}{l}\text { 7. How often during the last year } \\
\text { have you had a feeling of guilt or } \\
\text { remorse after drinking? }\end{array}$ & Never & $\begin{array}{l}\text { Less than } \\
\text { monthly }\end{array}$ & Monthly & Weekly & $\begin{array}{l}\text { Daily or } \\
\text { almost daily }\end{array}$ \\
\hline $\begin{array}{l}\text { 8. How often during the last year } \\
\text { have you been unable to remember } \\
\text { what happened the night before } \\
\text { because of your drinking? }\end{array}$ & Never & $\begin{array}{l}\text { Less than } \\
\text { monthly }\end{array}$ & Monthly & Weekly & $\begin{array}{l}\text { Daily or } \\
\text { almost daily }\end{array}$ \\
\hline $\begin{array}{l}\text { 9. Have you or someone else } \\
\text { been injured because of } \\
\text { your drinking? }\end{array}$ & No & & $\begin{array}{l}\text { Yes, but } \\
\text { not in the } \\
\text { last year }\end{array}$ & & $\begin{array}{l}\text { Yes, during } \\
\text { the last year }\end{array}$ \\
\hline $\begin{array}{l}\text { 10. Has a relative, friend, doctor, or } \\
\text { other health care worker been } \\
\text { concerned about your drinking or } \\
\text { suggested you cut down? }\end{array}$ & No & & $\begin{array}{l}\text { Yes, but } \\
\text { not in the } \\
\text { last year }\end{array}$ & & $\begin{array}{l}\text { Yes, during } \\
\text { the last year }\end{array}$ \\
\hline
\end{tabular}

Note: This questionnaire (the AUDIT) is reprinted with permission from the World Health Organization and the Generalitat Valenciana Conselleria De Benestar Social. To reflect standard drink sizes in the United States, the number of drinks in question 3 was changed from 6 to 5. A free AUDIT manual with guidelines for use in primary care is available online at www.who.org. 


\section{REFERRAL RESOURCES}

When making referrals, involve your patient and a parent or guardian in the decision and schedule a referral appointment while your patient is in the office. If available in your community, arrange for an interagency facilitator to help make sure your patient connects with the treatment provider.

\section{Finding evaluation and treatment options}

- For patients with insurance: Contact a behavioral health case manager at the insurance company for referrals.

- For patients who are uninsured or underinsured: Contact your local health department about substance abuse treatment services for adolescents.

- For older patients who are employed or in college: Ask about access to an employee assistance or school counseling program that includes substance abuse treatment.

- To locate adolescent treatment options in your area:

- Ask behavioral health practitioners affiliated with your practice for recommendations.

- Seek local directories of behavioral health services.

- Contact local hospitals and mental health service organizations.

- Call the National Drug and Alcohol Treatment Referral Routing Service (1-800-662-HELP) or visit the Substance Abuse Treatment Facility Locator Web site at www.findtreatment.samhsa.gov.

- For a helpful list of criteria for selecting a substance abuse treatment program for adolescents, see the American Association of Pediatrics Policy Statement on Substance Use Screening, Brief Intervention, and Referral to Treatment for Pediatricians (AAP Committee on Substance Abuse, in press).

\section{Finding support groups}

- Groups specific to your area: Through those knowledgeable about your local behavioral health options, seek groups that provide treatment aftercare and support to adolescent patients and their families.

- Nationwide groups: Consider contacting Alcoholics Anonymous (AA) to ask whether any local groups primarily draw young people (for phone numbers, visit www.aa.org). Note, however, that all AA groups are open to those of all ages at any time. To avoid a possible mismatch, it may be best to consider AA referrals only for older youth who have had a formal evaluation. For support groups for family members, contact Al-Anon (www.al-anon.alateen.org).

\section{Local resources}

List your local resources below. Make copies and keep them in exam rooms and other accessible locations. Develop working relationships with these resources to facilitate referrals and access to care. 


\section{REFERENCES}

Abar, C., Abar, B., \& Turrisi, R. (2009). The impact of parental modeling and permissibility on alcohol use and experienced negative drinking consequences in college. Addictive Behaviors, 34(6-7), 542-7.

American Academy of Family Physicians. (2008). Adolescent health care, confidentiality. Retrieved June 21, 2011, from www.aafp.org/online/en/ home/policy/policies/a/adol2.html

American Academy of Pediatrics. (2011). Coding for pediatrics, 16th edition. Elk Grove Village, IL: American Academy of Pediatrics.

American Academy of Pediatrics. (2010). Addressing mental health concerns in primary care: A clinician's toolkit. First edition. [CD-ROM]. Elk Grove Village, IL: American Academy of Pediatrics.

American Academy of Pediatrics Adolescent Health Update Editorial Board. (2007). Inspiring teens to change: Motivational interviewing can be used even in busy offices to help adolescents adopt healthy behaviors. AAP News, 28, 23-24.

American Academy of Pediatrics Committee on Substance Abuse. (in press). Policy statement: Substance use screening, brief intervention, and referral to treatment for pediatricians.

American Academy of Pediatrics Committee on Substance Abuse, \& Kokotailo, P. K. (2010). Alcohol use by youth \& adolescents: A pediatric concern. Pediatrics, 125(5), 1078-87.

American Medical Association. Health policies: Confidential health services for adolescents (H-60.965). Retrieved May 25, 2011, from www.ama-assn.org/resources/doc/alcohol/alc adolhealthcare.pdf

Berlan, E. D., \& Bravender, T. (2009). Confidentiality, consent, and caring for the adolescent patient. Current Opinion in Pediatrics, 21(4), 450-6.

Biglan, A., Brennan, P. A., Foster, S. L., \& Holder, H. D. (2004). Helping adolescents at risk: Prevention of multiple problem behaviors. New York: Guilford Press.

Brown, J. D., \& Wissow, L. S. (2009). Discussion of sensitive health topics with youth during primary care visits: Relationship to youth perceptions of care. Journal of Adolescent Health, 44(1), 48-54.
Brown, S. A., Donovan, J. E., McGue, M. K., Shulenberg, J. E., Zucker, R. A., \& Goldman, M. A. (2010). Youth alcohol screening workgroup II: Determining optimal secondary screening questions. Alcoholism: Clinical \& Experimental Research 34 (Supplement s2), 267A.

Brown, S. A., McGue, M., Maggs, J., Schulenberg, J., Hingson, R., Swartzwelder, S., Martin, C., Chung, T., Tapert, S. F., Sher, K., Winters, K. C., Lowman, C., \& Murphy, S. (2008). A developmental perspective on alcohol and youths 16 to 20 years of age. Pediatrics, 121 (Supplement 4), S290-310.

Centers for Disease Control and Prevention. (2008). QuickStats: Percentage of deaths from leading causes among teens aged 15-19 yearsNational Vital Statistics System, United States, 2005. Morbidity and Mortality Weekly Report, 57(45), 1234.

Centers for Disease Control and Prevention. (2007). Types of alcoholic beverages usually consumed by students in 9th-12th grades-Four States, 2005. Morbidity and Mortality Weekly Report, 56(29), 737-740.

Chen, C. M., Yi, H., \& Faden, V. B. (2011). NIAAA trends in underage drinking in the United States, 1991-2009, Surveillance Report \#91.

Clark, D. B., Gordon, A. J., Ettaro, L. R., Owens, J. M., \& Moss, H. B. (2010). Screening and brief intervention for underage drinkers. Mayo Clinic Proceedings, 85(4), 380-91.

Donovan, J. E. (2009). Estimated blood alcohol concentrations for child and adolescent drinking and their implications for screening instruments. Pediatrics, 123(6), e975-81.

English, A., Bass, L., Boyle, A. D., \& Eshragh, F. (2010). State minor consent laws: A summary, third edition. Chapel Hill, NC: Center for Adolescent Health \& the Law.

Erickson, S. J., Gerstle, M., \& Feldstein, S. W. (2005). Brief interventions and motivational interviewing with children, adolescents, and their parents in pediatric health care settings: A review. Archives of Pediatrics \& Adolescent Medicine, 159(12), 1173-80.

Ferreira, S. E., de Mello, M. T., Pompéia, S., \& de Souza-Formigoni, M. L. (2006). Effects of energy drink ingestion on alcohol intoxication. Alcoholism: Clinical and Experimental Research, 30(4), 598-605. 
Ford, C., English, A., \& Sigman, G. (2004). Confidential health care for adolescents: Position paper for the Society for Adolescent Medicine. Journal of Adolescent Health, 35(2), 160-7.

Ford, C. A., Millstein, S. G., Halpern-Felsher, B. L., \& Irwin, C. E., Jr. (1997). Influence of physician confidentiality assurances on adolescents' willingness to disclose information and seek future health care. A randomized controlled trial. Journal of the American Medical Association, 278(12), 1029-34.

Gold, M. A., \& Kokotailo, P. K. (2007). Motivational interviewing strategies to facilitate adolescent behavior change. Adolescent Health Update, 20(1), 1-10.

Grant, B. F., \& Dawson, D. A. (1997). Age at onset of alcohol use and its association with DSM-IV alcohol abuse and dependence: Results from the National Longitudinal Alcohol Epidemiologic Survey. Journal of Substance Abuse, 9, 103-10.

Hagan J. F., Shaw J. S., \& Duncan, P. M., eds. (2008). Bright futures: Guidelines for health supervision of infants, children, and adolescents, third edition. Elk Grove Village, IL: American Academy of Pediatric.

Hingson, R. W., Heeren, T., \& Winter, M. R. (2006). Age at drinking onset and alcohol dependence: Age at onset, duration, and severity. Archives of Pediatrics \& Adolescent Medicine, 160(7), 739-46.

Hutchinson, J. W., \& Stafford, E. M. (2005). Changing parental opinions about teen privacy through education. Pediatrics, 116(4), 966-71.

Jensen, C. D., Cushing, C. C., Aylward, B. S., Craig, J. T., Sorell, D. M., \& Steele, R. G. (2011). Effectiveness of motivational interviewing interventions for adolescent substance use behavior change: A meta-analytic review. Journal of Consulting and Clinical Psychology, 79(4), 433-40.

Johnston, L. D., O’Malley, P. M., Bachman, J. G., \& Schulenberg, J. E. (2011). Monitoring the Future national results on adolescent drug use: Overview of key findings, 2010. Ann Arbor: Institute for Social Research, The University of Michigan.

Johnston, L. D., O’Malley, P. M., Bachman, J. G., \& Schulenberg, J. E. (2010). Monitoring the Future national survey results on drug use, 1975-2009. Volume I: Secondary school students (NIH Publication No. 10-7584). Bethesda, MD: National Institute on Drug Abuse.
Knight, J. R., Sherritt, L., Harris, S. K., Gates, E. C., \& Chang, G. (2003). Validity of brief alcohol screening tests among adolescents: A comparison of the AUDIT, POSIT, CAGE, and CRAFFT. Alcoholism: Clinical \& Experimental Research, 27(1), 67-73.

Knight, J. R., Sherritt, L., Shrier, L. A., Harris, S. K., \& Chang, G. (2002). Validity of the CRAFFT substance abuse screening test among adolescent clinic patients. Archives of Pediatrics \& Adolescent Medicine, 156(6), 607-14.

Kulig, J. W., \& American Academy of Pediatrics Committee on Substance Abuse. (2005). Tobacco, alcohol, and other drugs: The role of the pediatrician in prevention, identification, and management of substance abuse. Pediatrics, 115(3), 816-21.

Lehrer, J. A., Pantell, R., Tebb, K., \& Shafer, M. A. (2007). Forgone health care among U.S. adolescents: Associations between risk characteristics and confidentiality concern. Journal of Adolescent Health, 40(3), 218-26.

Levy, S., Vaughan, B. L., \& Knight, J. R. (2002). Office-based intervention for adolescent substance abuse. Pediatric Clinics of North America, 49(2), 329-43.

Macgowan, M. J., \& Engle, B. (2010). Evidence for optimism: Behavior therapies and motivational interviewing in adolescent substance abuse treatment. Child \& Adolescent Psychiatric Clinics of North America, 19(3), 527-45.

McMorris, B. J., Catalano, R. F., Kim, M. J., Toumbourou, J. W., \& Hemphill, S. A. (2011). Influence of family factors and supervised alcohol use on adolescent alcohol use and harms: Similarities between youth in different alcohol policy contexts. Journal of Studies on Alcohol and Drugs, 72(3), 418-28.

Miller, W. R., Zweben, A., DiClemente, C. C., \& Rychtarik, R. G. (1992). Motivational enhancement therapy manual: A clinical research guide for therapists treating individuals with alcohol abuse and dependence. Rockville, MD: NIAAA.

Millstein, S. G., \& Marcell, A. V. (2003). Screening and counseling for adolescent alcohol use among primary care physicians in the United States.

Pediatrics, 111(1), 114-22. 
Morreale, M. C., Stinnett, A. J., \& Dowling, E. D., eds. (2005). Policy compendium on confidential health services for adolescents, second edition. Chapel Hill, NC: Center for Adolescent Health \& the Law.

Naar-King, S., \& Suarez, M. (2011). Motivational interviewing with adolescents and young adults. New York: Guildford Press.

National Institute on Alcohol Abuse and Alcoholism. (2011). Unpublished analysis of 2000-2009 data from the National Survey on Drug Use and Health (NSDUH), an annual nationwide survey sponsored by the Substance Abuse and Mental Health Services Administration.

National Institute on Alcohol Abuse and Alcoholism. (2010). Parenting to prevent childhood alcohol use. NIH Publication No. 10-7467.

O’Brien, M. C., McCoy, T. P., Rhodes, S. D., Wagoner, A., \& Wolfson, M. (2008). Caffeinated cocktails: Energy drink consumption, high-risk drinking, and alcohol-related consequences among college students. Academic Emergency Medicine, 15(5), 453-60.

O’Connor, E. A., Hollis, J. F., Polen, M. R., \& Lichtenstein, E. (1999). Adolescent health care visits: Opportunities for brief prevention messages. Effective Clinical Practice, 2(6), 272-6.

Reinert, D. F., \& Allen, J. P. (2007). The alcohol use disorders identification test: An update of research findings. Alcoholism: Clinical \& Experimental Research, 31(2), 185-99.

Rollnick, S., \& Miller, W. R. (1995). What is motivational interviewing? Behavioural and Cognitive Psychotherapy, 23(4), 325-334.

Rubak, S., Sandbaek, A., Lauritzen, T., \& Christensen, B. (2005). Motivational interviewing: A systematic review and meta-analysis. British Journal of General Practice, 55(513), 305-12.

Siegel, M. B., Naimi, T. S., Cremeens, J. L., \& Nelson, D. E. (2011). Alcoholic beverage preferences and associated drinking patterns and risk behaviors among high school youth. American Journal of Preventive Medicine, 40(4), 419-26.

Smith, G. T., Chung, T., Martin, C. S., Donovan, J. E., \& Windle, M. (2010). Youth alcohol screening workgroup I: Measuring consumption of alcohol as a screener in children and adolescents. Alcoholism: Clinical \& Experimental Research 34 (Supplement s2), 276A.
Squeglia, L. M., Jacobu, J., \& Tapert, S. F. (2009). The influence of substance use on adolescent brain development. Clinical EEG \& Neuroscience Journal, 40(1), 31-8.

Substance Abuse and Mental Health Services Administration. (2010). Results from the 2009 National Survey on Drug Use and Health: Volume I. Summary of national findings (Office of Applied Studies, NSDUH Series H-38A, HHS Publication No. SMA 10-4856Findings). Rockville, MD.

Tevyaw, T. O., \& Monti, P. M. (2004).

Motivational enhancement and other brief interventions for adolescent substance abuse: Foundations, applications and evaluations. Addiction, (Supplement 2), 63-75.

Tripodi, S. J., Bender, K., Litschge, C., \& Vaughn, M. G. (2010). Interventions for reducing adolescent alcohol abuse: A meta-analytic review. Archives of Pediatrics \& Adolescent Medicine, 164(1), 85-91.

U.S. Preventive Services Task Force. (2004). Screening and behavioral counseling interventions in primary care to reduce alcohol misuse. Retrieved August 31, 2011, from www. uspreventiveservicestaskforce.org/3rduspstf/ alcohol/alcomisrs.htm

Van Hook, S., Harris, S. K., Brooks, T., Carey, P., Kossack, R., Kulig, J., \& Knight, J. R.; New England Partnership for Substance Abuse Research. (2007). The "Six T's": Barriers to screening teens for substance abuse in primary care. Journal of Adolescent Health, 40(5), 456-61.

Wachtel, T., \& Staniford, M. (2010). The effectiveness of brief interventions in the clinical setting in reducing alcohol misuse and binge drinking in adolescents: A critical review of the literature. Journal of Clinical Nursing, 19(5-6), 605-20.

Walls, T. A., Fairlie, A. M., \& Wood, M. D. (2009). Parents do matter: A longitudinal two-part mixed model of early college alcohol participation and intensity. Journal of Studies on Alcohol and Drugs, 70(6), 908-18.

Walton, M. A., Chermack, S. T., Shope, J. T., Bingham, C. R., Zimmerman, M. A., Blow, F. C., \& Cunningham, R. M. (2010). Effects of a brief intervention for reducing violence and alcohol misuse among adolescents: A randomized controlled trial. Journal of the American Medical Association, 304(5), 527-35.

Wood, M. D., Read, J. P., Mitchell, R. E., \& Brand, N. H. (2004). Do parents still matter? Parent and peer influences on alcohol involvement among recent high school graduates. Psychology of Addictive Behaviors, 18(1), 19-30. 


\section{ADDITIONAL RESOURCES}

\section{For health care professionals}

\section{Screening and risk assessment}

National Institute on Alcohol Abuse and Alcoholism (NIAAA)

www.niaaa.nih.gov

- Web page for this Guide - additional background, resources, and updates www.niaaa.nih.gov/YouthGuide

- General information about alcohol, including standard drink sizes www.rethinkingdrinking.niaaa.nih.gov

American Academy of Pediatrics (AAP) www.aap.org

- National Committee on Substance Abuse-policy statements www.aap.org/visit/cmte35.htm

- Children's Mental Health in Primary Care- toolkit and other resources www.aap.org/commpeds/dochs/ mentalhealth/

\section{Confidential care}

Center for Adolescent Health and the Law-monographs on minor consent laws and professional association policies www.cahl.org

Society for Adolescent Health and Medicinesample confidentiality statement, billing guidance, and other clinical care resources www.adolescenthealth.org

\section{Motivational interviewing}

For background and training information, visit:

- www.motivationalinterview.org

- www.motivationalinterview.net

\section{Treatment locator}

Substance Abuse Treatment Facility Locator (seek centers specializing in adolescents) 1-800-662-HELP or www.findtreatment.samhsa.gov

\section{For parents}

\section{Publications}

NIAAA's Parenting to Prevent Childhood Alcohol Abuse

pubs.niaaa.nih.gov/publications/adolescent/ adolflyer.htm

NIAAA's Make a Difference: Talk to Your Child About Alcohol pubs.niaaa.nih.gov/publications/MakeADiff HTML/makediff.htm

Substance Abuse and Mental Health Services Administration (SAMHSA)'s Start Talking Before They Start Drinking: A Family Guide www.stopalcoholabuse.gov/media/Underage Brochure 508final.pdf

AAP's A Parent's Guide to Teen Parties www.healthychildren.org/English/ages-stages/ teen/Pages/A-Parents-Guide-To-Teen-Parties.aspx 


\section{Web sites}

SAMHSA's Talk Early, Talk Often,

Get Others Involved

www.underagedrinking.samhsa.gov/default.aspx

AAP Parenting Web Site: www.healthychildren. org; in particular, "Alcohol—-The Most

Popular Choice": www.healthychildren.org/ English/ages-stages/teen/substance-abuse/ pages/Alcohol-The-Most-Popular-Choice.aspx

The Partnership at DrugFree.org www.drugfree.org/

NIAAA's College Drinking Prevention Web site, parents page www.collegedrinkingprevention.gov/ CollegeParents

\section{Driving and safety agreements}

AAP's Parent-Teen Driving Agreement www.healthychildren.org/English/ages-stages/ teen/safety/pages/Teen-Driving-Agreement.aspx

Students Against Destructive Decisions

"Contract for Life"

www.sadd.org/contract.htm

\section{For patients}

For ages 11 to 13-NIAAA's The Cool Spot, an interactive Web site to help kids identify and resist peer pressure to drink www.thecoolspot.gov/

Support for patients whose parents have drinking problems:

- Al-Anon Family Groups, including Alateen www.al-anon.alateen.org

- National Association for Children of Alcoholics "Just 4 Kids" page www.nacoa.org/kidspage.html

\section{Underage drinking facts and figures}

NIAAA's Underage Drinking Research Initiative

www.niaaa.nih.gov/AboutNIAAA/NIAAA

SponsoredPrograms/Pages/underage.aspx

NIAAA's Alcohol Research \& Health journal issue on underage drinking (2009)

pubs.niaaa.nih.gov/publications/arh321/

toc32-1.htm

Centers for Disease Control and Prevention's page on Alcohol and Public Health www.cdc.gov/Alcohol/

Monitoring the Future www.monitoringthefuture.org

Report to Congress on the Prevention and Reduction of Underage Drinking (May 2011) www.store.samhsa.gov/shin/content/SMA114645/SMA11-4645.pdf 
Notes 
To order more copies of this Guide and Pocket Guide set, free of charge, visit www.niaaa.nih.gov/YouthGuide or call 301-443-3860 

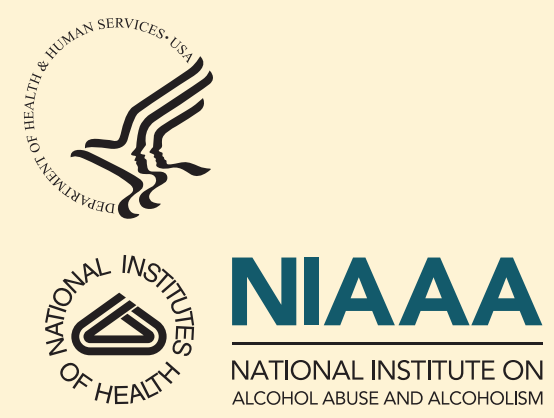

Produced in collaboration with the

American Academy of Pediatrics

DEDICATED TO THE HEALTH OF ALL CHILDREN" 